\title{
(2) \\ Proving that Traditional Knowledge Works: The antibacterial activity of Northern Peruvian medicinal plants
}

\author{
Bussmann, R.W., A. Glenn, D. Sharon, G. Chait, D. Díaz, \\ K. Pourmand, B. Jonat, S. Somogy, G. Guardado, C. \\ Aguirre, R. Chan, K. Meyer, A. Rothrock \& A. Townesmith
}

\section{Research}

\begin{abstract}
Bacterial infections and inflammation are among the ailments treated by traditional healers. The World Health Organization has expressed high interest in Traditional Medicine (TM), and it is important to demonstrate scientifically that the remedies employed in folk medicine are indeed therapeutically active. In order to evaluate the antibacterial activity of species used in traditional medicine in Northern Peru, 525 plant samples of at least 405 species were tested in simple agar-bioassays for antibacterial activity under simple laboratory conditions in a private clinic in Trujillo, Peru. Antibacterial activity was investigated against Staphylococcus aureus Rosenbach 1884, Escherichia coli (Migula 1895) Castellani \& Chalmers 1919, Salmonella enterica Typhi (ex Kauffmann \& Edwards 1952) Le Minor \& Popoff 1987, and Pseudomonas aeruginosa (Schröter 1872) Migula 1900. The aim of the study was to scientifically test whether plants used in TM for the treatment of infections showed antibacterial activity, and to delineate a number of candidates for further in-depth study of their Minimum Inhibitory Concentration (MIC) and toxicity. One-hundred-ninety-three ethanolic extracts and 31 water extracts were active against $S$. aureus. In twentyone cases only the water extract showed activity. None of the aqueous extracts were active against the other three bacteria, with the activity of the ethanolic extracts also much reduced, as only 36 showed any activity against $E$. coli, and 3 each against $S$. enterica Typhi and $P$. aeruginosa. Two-hundred-twenty-five extracts came from species that are traditionally employed against bacterial infections. One-hundred-sixty-six $(73.8 \%)$ of these were active against at least one bacterium. Of the three-hundred extracts from plants without traditional antibacterial use, only $96(32 \%)$ showed any activity Plants used for respiratory disorders, inflammation/infection, wounds, diarrhea, and to prevent post partum infections were efficacious in 70$88 \%$ of the tests. Plants used for "kidney inflammation"
\end{abstract}

had a much lower efficacy against bacteria and fell within the range of species that are traditionally used to treat other bodily disorders.

\section{Resumen}

Infecciones bacterianas e inflamación se encuentran entre las enfermedades tratadas por curanderos tradicionales. La Organización Mundial de Salud se ha expresada como altamente interesada en la Medicina Tradicional, y es importante demostrar científicamente que los remedios usados en la medicina popular de veras son terapéuticamente activos. En este trabajo evaluamos la propiedad antibacteriana de 525 muestras de plantas medicinales del Perú septentrional de mínimo 405 especies contra Staphylococcus aureus Rosebach 1884 Escherichia coli (Migula

\section{Correspondence}

R.W. Bussmann, A. Glenn, D. Sharon, K. Meyer, A. Rothrock, A. Townesmith, William L. Brown Center, Missouri Botanical Garden, P.O. Box 299, St. Louis, Missouri 63166-0299, U.S.A.

rainer.bussmann@mobot.org

G. Chait, San Diego State University, 5500 Campanile Dr., San Diego, California 92182-4616, U.S.A.

D. Díaz, Clínica Anticona, Laboratorio Clínico, Prolongación Unión 2390, Trujillo, PERU.

K. Pourmand, B. Jonat, State University of New York at Stony Brook, Stony Brook, New York, U.S.A.

S. Somogy, Rosenweg 62, 77933 Lahr, GERMANY.

G. Guardado, C. Aguirre, R. Chan, University of California at Berkeley, Berkeley, California 94720, U.S.A.

Ethnobotany Research \& Applications 9:067-096 (2011)

Published: February 25, 2011 
1895) Castellani \& Chalmers 1919, Salmonella enterica Typhi (ex Kauffmann \& Edwards 1952) Le Minor \& Popoff 1987 e Pseudomonas aeruginosa (Schröter 1872) Migula 1900 , usando un método de difusión en agar bajo de condiciones simples de laboratorio en Trujillo, Perú. La meta de este estudio fue de científicamente probar si plantas usadas en la Medicina Tradicional para tratar infecciones mostraron actividad antibacteriana, y para delinear candidatos para estudios futuros de Concentración Inhibitoria Mínima y toxicidad. Ciento noventa y tres extractos etanolicos y 31 extractos en agua mostraron actividad en contra de $S$. aureus. En 21 casos solo los extractos acuosos fueron eficaces. Ninguno de los extractos acuosos tuvo actividad contra las otras bacterias, y solo 36 de los etanolicos mostraron eficaz contra $E$. coli, y 3 en cada caso contra S. enterica Typhi e $P$. aeruginosa. Doscientos veinticinco extractos pertenecieron a especies tradicionaImente usadas como antibacterianas. De estos $73.8 \%$ fueron activos. De los 300 extractos de plantas no tradicionalmente usadas contra bacterias, solo $32 \%$ tuvieron un efecto positive. Plantas usadas para el tratamiento de infecciones respiratorias, inflamación/ infección, heridas, diarrea e infecciones después del parto fueron eficaces en $70-88 \%$ de los casos. Plantas usadas para inflamaciones de los riñones y otros desordenes tuvieron una eficaz mucho mas baja en contra de bacterias.

\section{Introduction}

In developing countries, Traditional Medicine (TM) is often the only accessible and affordable treatment available. In Latin America, the World Health Organization (WHO) Regional Office for the Americas (AMRO/PAHO) reports that $71 \%$ of the population in Chile and $40 \%$ of the population in Colombia has used TM. In many Asian countries TM is widely used, even though Western Medicine is often readily available. In Japan, $60-70 \%$ of allopathic doctors prescribe traditional medicines for their patients. In the US the number of visits to providers of Complementary Alternative Medicine (CAM) now exceeds by far the number of visits to all primary care physicians (WHO 1999a, b, 2002).

CAM is becoming increasingly popular in many developed countries. Forty-two percent of the population of the U.S.A. have used CAM at least once (WHO 1998), and a national survey reported the use of at least one of 16 alternative therapies increased from $34 \%$ in 1990 to $42 \%$ in 1997 (UNCTD 2000).

The expense for the use of TM and CAM is exponentially growing in many parts of the world. The 1997 out-ofpocket CAM expenditure was estimated at $\$ 2.7$ billion in the U.S.A. The world market for herbal medicines based on traditional knowledge was estimated at US $\$ 60$ billion already over a decade ago (Breevort 1998). It is however important to demonstrate scientifically that the remedies employed in folk medicine are indeed therapeutically active (Baker et al. 1995, Cox \& Balick 1994, Elisabetsky \& Castilhos 1990, Farnsworth et al. 1985, Muñoz \& Sauvain 2002, Schultes 1994).

Peru is a country rich in biodiversity. For millennia, traditional healers have used the flora to treat ailments. The same plants are still being used today. Traditional Medicine continues to be very popular since a large part of the population has either no access to, or cannot afford, Western Medicine. Bacterial infections and inflammation are among the ailments treated by traditional healers. Northern Peru is believed to be the center of the Central Andean Health Axis (Camino 1992, 1999), and traditional medicinal practices in this region remain an important component of everyday life (Bussmann 2006, Bussmann \& Sharon 2006, De Feo 1992, Joralemon \& Sharon 1993, Polia 1988, Sharon 1978, 1980, 1994, 2000, Sharon \& Bussmann 2006). TM is also gaining respect by national governments and health providers. Peru's National Program in Complementary Medicine and the Pan American Health Organization recently compared Complementary Medicine to allopathic medicine in clinics and hospitals operating within the Peruvian Social Security System (EsSalud 2000). According to the WHO (2002), the sustainable cultivation and harvesting of medicinal plant species is one of the most important challenges in the next few years. The WHO has expressed high interest in TM.

Plants with potential medicinal activity have recently come to the attention of Western scientists, and studies have reported that some are bioactive (e.g., Perumal Samy \& Ignacimuthu 2000). Potentially active compounds have been isolated from a few of the plants tested (D'Agostino et al. 1995 a, b, Okuyama et al. 1994, Rodriguez et al. 1994, Umana \& Castro 1990).

Plant species from the Cordillera Blanca, one of the highaltitude areas of Peru, have been studied in recent years for their antimicrobial, anti-cancer, and wound-healing activities (Bussmann et al. 2008, Hammond et al. 1998, Lee et al. 1999, Neto et al. 2002, Villegas et al. 1997). However, despite the fact that the center of healing traditions in Northern Peru is located in the Trujillo / Chiclayo coastal region, no studies had been undertaken in this area until the work of the Minority Health Disparity International Research Training (MHIRT) Peru.

In this communication we report on antibacterial assays for 391 plant species with a wide range of traditional uses, conducted under simple laboratory conditions in a private clinic in Trujillo. The goal of this investigation was to validate the medicinal use of these plants. We hypothesize that plants that are traditionally used to treat illnesses caused by bacteria have a higher likelihood to being efficacious than plants that are not used traditionally as anti- 


\section{Bussmann et al. - Proving that Traditional Knowledge Works: The antibacterial activity of Northern Peruvian medicinal plants}

bacterials, in particular plants that are normally employed for purely spiritual healing purposes. However, we hypothesize that plants that are employed as baths for spiritual cleansing, and thus come in direct contact with the skin of the patient, might have measurable antibacterial effects, while plants that are used in protective amulets (seguros) are not active.

\section{Materials and Methods}

\section{Plant Material}

Plants in Peru were collected in the field, in markets, and at the homes of traditional healers (curanderos) in Northern Peru (Figure 1) in August-September 2001, July-August 2002, July-August 2003, June-August 2004, July-August 2005, July-August 2006, June-August 2007, JuneAugust 2008, March-April 2009 and June-August 2009. A total of 116 informants ( 6 healers and 110 market venders, of which 20 also acted as healers) in the Trujillo and Chiclayo area were interviewed using structured questionnaires. The informants were always provided with fresh plant material, either collected with them, by them, or available at their market stands. The questionnaires did not include any leading reference as to disease concepts. The participants were only asked simple questions along the lines "What is this plant used for, which part, which quantity, how is it prepared, are any other plants added to the mixture." All questions were asked in the same order. All informants were of Mestizo origin, and spoke only Spanish as their native language. The study covered the four existing medicinal plant markets of the region, and included all venders present. All interviews were conducted with the same set of participants. The allopathic disease concept of "infection" was found to cover not only topical bacterial, viral and fungal diseases, but also external and internal inflammatory processes, when looked at from the local healing perspective. For this reason, all plants used to treat such symptoms were included in the study. The specimens are registered under the collection series "RBU/PL," "ISA," "GER," "JULS," "EHCHL," "VFCHL," "TRUBH," and "TRUVANERICA," depending on the year of fieldwork and collection location. Surveys were conducted in Spanish by fluent speakers. Surveyors would approach healers, collectors and market vendors and explain the premise for the study, including the goal of conservation of medicinal plants in the area.

Vouchers of all specimens were deposited at the Herbario Truxillensis (HUT, Universidad Nacional de Trujillo), and Herbario Antenor Orrego (HAO, Universidad Privada Antenor Orrego Trujillo). In order to recognize Peru's rights under the Convention on Biological Diversity, most notably with regard to the conservation of genetic resources in the framework of a study treating medicinal plants, the identification of the plant material was conducted entirely in Peru. Plant material was identified by the authors, using available floras as indicated in the nomenclature section, as well as herbarium vouchers in the herbaria where material was deposited. No plant material was exported in any form whatsoever.

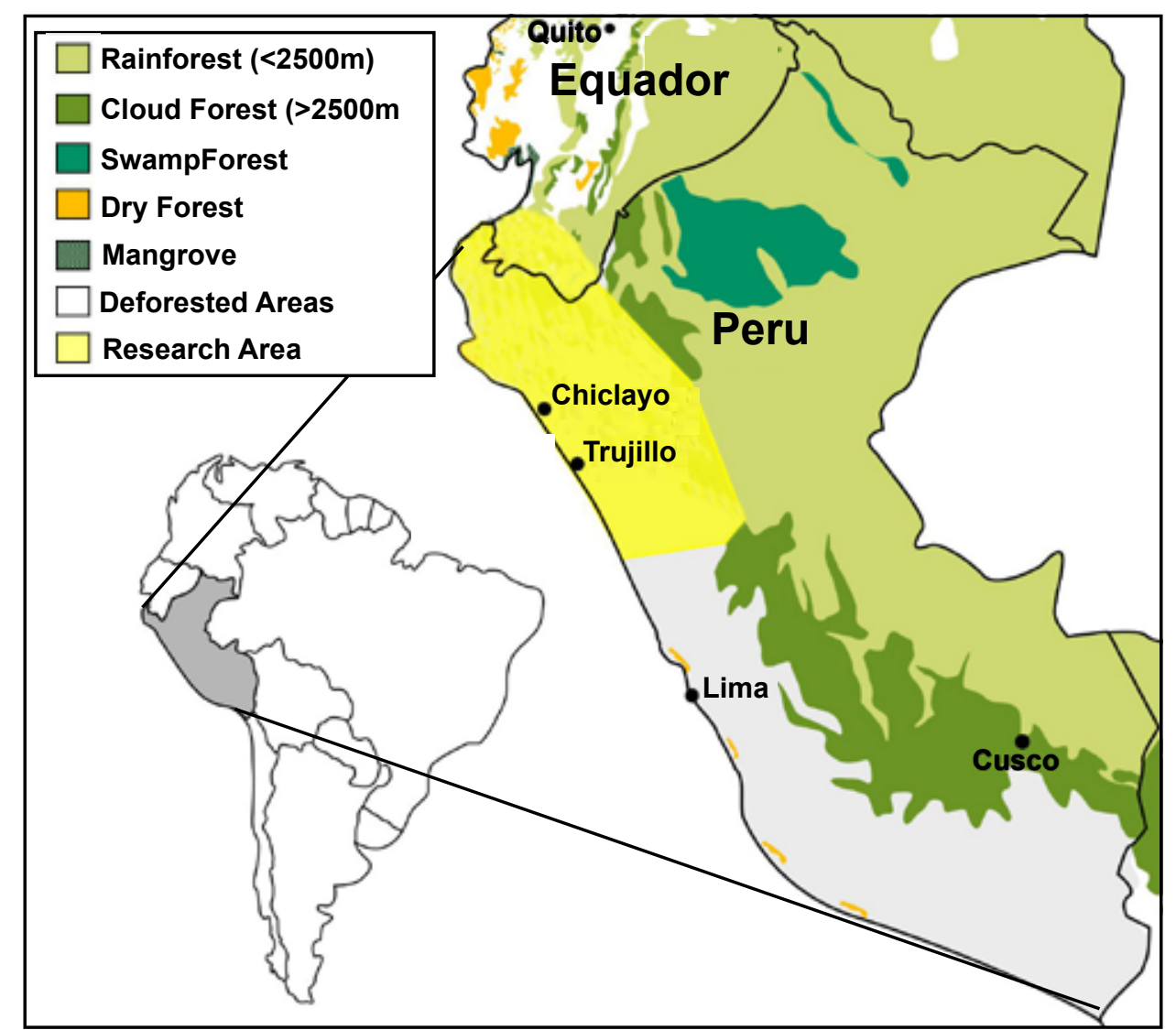

Figure 1. Trujillo and Chiclayo research area of northern Peru. 


\section{Nomenclature}

The nomenclature of genera and species follows the Catalogue of the Flowering Plants and Gymnosperms of Peru (Brako Zarucchi 1993) and the Catalogue of the Vascular Plants of Ecuador (Jørgensen \& León-Yanez 1999). Species were identified using the available volumes of the Flora of Peru (McBride 1936-1981), as well as Jørgensen and Ulloa Ulloa (1994), Pestalozzi (1998), and Ulloa Ulloa and Jørgensen (1993), and the available volumes of the Flora of Ecuador (Sparre \& Harling 1978-2009), and reference material in the herbaria HUT, HAO, QCA, LOJA and QCNE. The plant family nomenclature was updated using the TROPICOS database (Tropicos 2010) which follows the Angiosperm Phylogeny Working Group III system of classification.

\section{Disease concepts}

In the context of our study, healers and market vendors used the terms "inflammation" and "infection" interchangeably for any indication that, to their understanding, was caused by a bacterial infection. We maintain this concept by simply using "inflammation" as a term that signifies potential antibacterial activity. In addition, we hypothesize that plants employed by healers for their concepts of "bronchitis, pneumonia, cough, wounds, diarrhea, kidney and urinary tract inflammation, blood purification and postpartum infections" also to be antibacterial, because in all these cases a bacterial infection could be suspected.

On the contrary, plants used to treat illnesses described as "diabetes, high blood pressure, arthritis, asthma, intestinal discomfort, or used as antihelminthics, anti-parasitics, menstrual regulation, abortion, contraceptive" etc. were clearly seen by the healers involved as non-antibacterial. We maintained this concept for our study.

A large part of the Peruvian pharmacopoeia (over $40 \%$, Bussmann \& Sharon 2006) is employed for "spiritual" healing. In such cases patients are either subjected to a healing bath, thus an herbal concoction coming in direct contact with the skin of the patient, or receive a seguro, a flask or bottle containing herbs in alcohol. The latter however is not ingested or allowed to come in direct contact with the patient in any way, but rather serves basically as an amulet. Because of their high abundance, "spiritually" used plants provide an ideal comparison group to antibacterial plants. In addition, cleansing baths are often employed when the healer suspects that sorcery has caused an illness, often manifesting as visible inflammation. For this reason, we hypothesized that plants of this kind are in fact antibacterial, although the healers would not mention them when addressing the western effect concept.

\section{Preparation of Extracts}

For each species tested, above ground material (in case of trees: leaves or bark as indicated by the collaborating healers) was collected during the same time period to avoid any seasonal variations, and the entire material was used for extract preparation. This corroborates with the traditional preparation (Bussmann \& Sharon 2006). Plant material was dried at $35^{\circ} \mathrm{C}$ for three days. After drying, the material was ground with an industrial grinder, and 2 samples of $5 \mathrm{~g}$ of plant material each were weighed out. Traditionally most plants are prepared in water extracts. In order to investigate if this method yielded the best antibacterial results, or if an ethanol extraction would prove more effective against bacteria, one sample was submerged in $100 \mathrm{ml}$ of $96 \%$ ethanol and left to macerate for 7 days, while another sample was submerged in $100 \mathrm{ml}$ of boiling distilled water and left to macerate for $24 \mathrm{~h}$. After maceration the plant material was filtered using standard $10 \mathrm{~cm}$ filters and $100 \mathrm{ml} 96 \%$ ethanol was added to the water extracts to allow faster solvent removal. The solvent was then evaporated to complete dryness using a standard Buchi rotary-evaporator. The resulting dry extracts were re-suspended in $5 \mathrm{ml}$ distilled water. In order to determine the real concentration of each extract, $1 \mathrm{ml}$ of previous homogenization of the respective extracts was removed and again completely oven-dried and then weighed to determine the exact amount of extract per $\mathrm{ml}$ of final solution.

\section{Antimicrobial assays}

\section{Bacteria}

Staphylococcus aureus Rosenbach 1884 ATCC 25923, Escherichia coli (Migula 1895) Castellani \& Chalmers 1919 ATCC 25922, Salmonella enterica (ex Kauffmann \& Edwards 1952) Le Minor \& Popoff 1987 serogroup Typhi (from a patient sample), and Pseudomonas aeruginosa (Schröter 1872) Migula 1900 (from a patient sample) were used for the current study.

\section{Bioassays}

The antibacterial activity of the crude plant extracts was determined using an agar-diffusion method (Koneman et al. 1997). Bacterial strains were obtained as listed above. Bacterial cultures were grown on $5 \%$ sheep red blood agar (SBA) and then inoculated onto Mueller-Hinton Agar (PML) for testing.

Following the initial incubation, bacteria were suspended in $10 \mathrm{ml}$ of distilled water and their concentration equilibrated to a $0.5 \mathrm{McF}$ arland standard. Using a sterile cotton swab, each sample was transferred onto Mueller-Hinton Agar. Six millimeter blank paper disks were then saturated with $10 \mu \mathrm{l}$ of each plant extract, dried, and applied to the agar surface. Disks with Doxycycline (for $S$. aureus assays, $3 \mu \mathrm{g} / \mathrm{ml}, 17 \mathrm{~mm}$ inhibition), Ampicillin (for $E$. coli 


\section{Bussmann et al. - Proving that Traditional Knowledge Works: The antibacterial activity of Northern Peruvian medicinal plants}

assays $1 \mu \mathrm{g} / \mathrm{ml}, 15 \mathrm{~mm}$ inhibition), Ceftriaxone (for $S$. enterica Typhi assays, $3 \mu \mathrm{g} / \mathrm{ml}, 8 \mathrm{~mm}$ inhibition) and Ciprofloxacin (for $P$. aeruginosa assay, $0.5 \mu \mathrm{g} / \mathrm{ml}, 10 \mathrm{~mm}$ inhibition) were applied as controls. These respective antibiotics were chosen because they are often employed as first line antibiotics in the respective bacterial infections. Disks with distilled water were used as negative controls. Plates were incubated at $37^{\circ} \mathrm{C}$. After $24 \mathrm{~h}$, zones of inhibition appearing around disks were measured and recorded in millimeters. At least three replicates were run for each assay. The antibiotic controls showed an inhibition zone of at least $6 \mathrm{~mm}$ after $24 \mathrm{~h}$ exposure in all assays. Extracts from plant species were considered anti-bacterially active if the inhibition zone was least $6 \mathrm{~mm}$.

\section{Results}

In order to evaluate the antibacterial activity of species used in TM in Northern Peru, 525 plant samples of at least 405 species were tested in simple agar-bioassays for antibacterial activity against $S$. aureus, E. coli, S. enterica Typhi and $P$. aeruginosa. Table 1 shows the results of the antibacterial assays. A much larger number of ethanolic plant extracts showed any antibacterial activity compared to water extracts for all antibacterial activity. One-hundred-ninety-three ethanolic extracts and 31 water extracts were active against $S$. aureus. In twenty-one cases only the water extract showed activity (for all bacterial species) compared to ethanol only. None of the aqueous extracts were active against the other three bacteria, with the activity of the ethanolic extracts also much reduced, as only 36 showed any activity against $E$. coli, and 3 each against

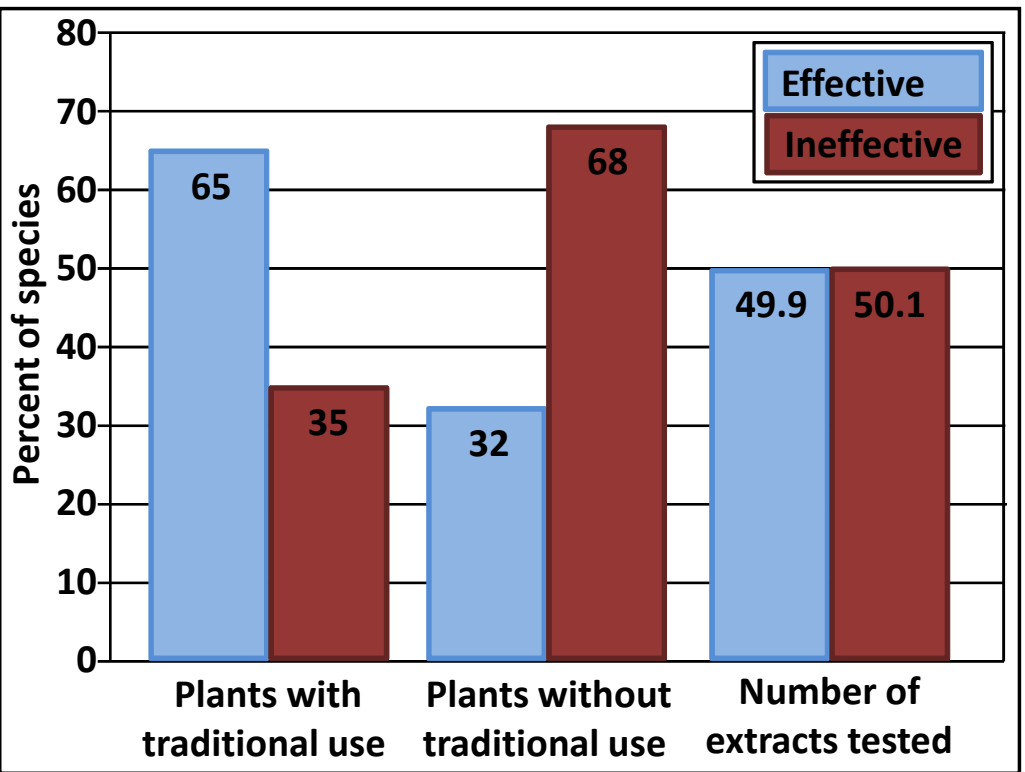

Figure 2. Evaluation of 225 plant species extracts that are traditionally employed against bacterial infections in the area of Trujillo and Chiclayo, northern Peru.
S. enterica Typhi and $P$. aeruginosa. Eighteen ethanol extracts were effective against both $E$. coli and $S$. aureus, while in two cases the ethanol extract showed activity against $E$. coli and the water extract against $S$. aureus. The ethanol extract of Dioscorea trifida L.f. was effective against $E$. coli, $S$. aureus and $P$. aeruginosa. Caesalpinia spinosa (Molina) Kuntze was the only species that showed high activity against all bacteria, including $S$. enterica Ttyphi and $P$. aeruginosa, when extracted in ethanol. This is of particular interest for potential further research.

Two-hundred-twenty-five extracts came from plant species that are traditionally employed against bacterial infections. One-hundred sixty-six $(73.8 \%)$ of these were active against at least one bacterium. Of the three-hundred extracts from plants without traditional antibacterial use, only $96(32 \%)$ showed any activity (Figure 2$)$. This shows clearly that plants traditionally used as antibacterial had a much higher likelihood to be antibacterially active than plants without traditional anti-bacterial use. However, the efficacy of plants used traditionally for antibacterial related applications did vary, which underlines the need for studies aiming to clearly understand traditional disease concepts. Plants used for respiratory disorders, inflammation/ infection, wounds, diarrhea, and to prevent postpartum infections were efficacious, based on antibacterial activity, in $70-88 \%$ of the tests. Plants used for "kidney inflammation" had a much lower efficacy against bacteria, and fell within the range of species that are traditionally used to treat other bodily disorders. Only species used for spiritual/ritual treatments scored worse. Of these only $22 \%$ showed some antibacterial; activity (Figures 3, 4). However, amongst the "spiritual" plants $38 \%$ of the species used for cleansing baths did in fact show activity, while only $15 \%$ of the plants often used in protective amulets (mostly species with the families of Lycopodiaceae and Caprifoliaceae) showed limited antibacterial activity.

A variety of species showed higher efficacy than the control antibiotics employed: Ambrosia peruviana Willd., Iresine herbstii Hook., Niphogeton dissecta (Benth.) J.F. Macbr., Opuntia ficus-indica (L.) Mill., Smilax kunthii Killip \& C.V. Morton were particular effective against E. coli. Berberis buceronis J.F. Macbr., Caesalpinia paipai Ruiz \& Pav., C. spinosa, Cestrum strigilatum Ruiz \& Pav., Cydista aequinoctialis (L.) Miers, D. trifida, Escallonia pendula (Ruiz \& Pav.) Pers., Escobedia grandiflora (L.f.) Kuntze, Eucalyptus citriodora Hook., Eucalyptus globulus Labill., Eugenia obtusifolia Cambess., Eustephia coccinea Cav., Gallesia integrifolia (Spreng.) Harms, 
Table 1. Antibacterial activity of 525 plant samples from 405 species used in traditional medicine in Northern Peru. Each were tested in simple agar-bioassays for antibacterial activity against Staphylococcus aureus Rosenbach 1884, Escherichia coli (Migula 1895) Castellani \& Chalmers 1919, Salmonella enterica (ex Kauffmann \& Edwards1952) Le Minor \& Popoff 1987 serogroup Typhi and Pseudomonas aeruginosa (Schröter1872) Migula 1900. Ethanol extracts noted in black, Water extracts noted in red. The positive control antibiotics led to bacterial inhibition in all assays. For details see Materials and Methods. The negative control (a disk with distilled water) did not cause any antibacterial effect in any assay. Antibacterial species are noted as:

Plants with efficacy AND traditional antibacterial use.

\section{Plants with traditional antibacterial use BUT WITHOUT efficacy \\ Plants with efficacy, but NOT traditionally used as antibacterial.}

Traditional applications: Abortifacient (Ab); Asthma (As); Arthritis (Ar); Blood pressure (Bp); Blood purification (BI); Bronchitis(Br); Contraceptive(C); Diabetes (Db); Diarrhea (Dr); Infection (If); Inflammation (In); Intestinal (It); Kidney Inflammation (K); Nerves (N); Parasites (Pa); Postpartum infection (Pi); Respiration (R); Spiritual cleansing(S); Wounds (W).

\begin{tabular}{|c|c|c|c|c|c|c|c|c|}
\hline \multirow[t]{2}{*}{$\begin{array}{l}\text { Plant Family } \\
\text { Species }\end{array}$} & \multirow[t]{2}{*}{ Common name } & \multirow[t]{2}{*}{$\begin{array}{l}\text { Collector } \\
\& \text { Col\# }\end{array}$} & \multicolumn{5}{|c|}{$\begin{array}{l}\text { Inhibition diameter } \\
(\mathrm{mm}) \text {. Blank cells } \\
\text { indicate lack of } \\
\text { antibacterial activity }\end{array}$} & \multirow[t]{2}{*}{$\begin{array}{l}\text { Traditional } \\
\text { application }\end{array}$} \\
\hline & & & نे & 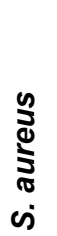 & 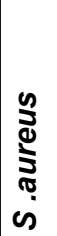 & 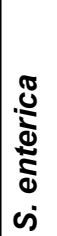 & 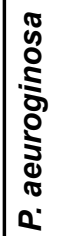 & \\
\hline \multicolumn{9}{|l|}{ Pteridaceae } \\
\hline $\begin{array}{l}\text { Adiantum concinnum Humb. \& } \\
\text { Bonpl. ex Willd. }\end{array}$ & Culantrillo & ACR91 & & 8 & & & & $\mathrm{BI}$ \\
\hline \multicolumn{9}{|l|}{ Amaranthaceae } \\
\hline $\begin{array}{l}\text { Alternanthera halimifolia } \\
\text { (Lam.) Standl. ex Pittier }\end{array}$ & Sanguinara & KMM468 & 10 & & & & & In \\
\hline $\begin{array}{l}\text { Alternanthera porrigens } \\
\text { (Jacq.) Kuntze }\end{array}$ & Moradilla & $\begin{array}{l}\text { AKT149/ } \\
\text { KMM395 }\end{array}$ & & & & & & $\begin{array}{l}\text { Blood } \\
\text { circulation }\end{array}$ \\
\hline Alternanthera villosa Kunth & Hierba de Oso & ACR 103 & & & & & & $S$ \\
\hline Amaranthus hybridus L. & Yuyo & GER190 & & 11 & & & & In \\
\hline Chenopodium ambrosioides L. & Paico & ACR31 & & & & & & Anthelminthic \\
\hline Gomphrena globosa L. & Siempre viva & ACR101 & & & & & & $S$ \\
\hline Iresine herbstii Hook. & Color & ACR162 & 17 & & & & & $\ln$ \\
\hline Iresine herbstii Hook. & Sanguinaria & JULS75 & 10 & 16 & & & & In \\
\hline \multicolumn{9}{|l|}{ Amaryllidaceae } \\
\hline Allium sativum $\mathrm{L}$. & Ajo & ACR107 & & & & & & As \\
\hline Eustephia coccinea Cav. & Pumapara & RBU/PL313 & & 7 & & & & $\ln$ \\
\hline \multirow[t]{3}{*}{ Eustephia coccinea Cav. } & Para Para & ACR138 & & 13 & 20 & & & In \\
\hline & Fosforito & KMM542 & & & & & & $S$ \\
\hline & Pumapara & ACR119 & & & & & & In \\
\hline \multicolumn{9}{|l|}{ Anacardiaceae } \\
\hline Mauria heterophylla Kunth & Chacur & $\begin{array}{l}\text { ACR77/ } \\
\text { JULS17 }\end{array}$ & 14 & 22 & & & & $\ln$ \\
\hline Schinus molle L. & Molle & KMM404 & & & & & & $\ln$ \\
\hline Schinus molle L. & Molle & JULS196 & & 14 & & & & In \\
\hline
\end{tabular}


Bussmann et al. - Proving that Traditional Knowledge Works: The antibacterial activity of Northern Peruvian medicinal plants

\begin{tabular}{|c|c|c|c|c|c|c|c|c|}
\hline \multirow[t]{2}{*}{$\begin{array}{l}\text { Plant Family } \\
\text { Species }\end{array}$} & \multirow[t]{2}{*}{ Common name } & \multirow[t]{2}{*}{$\begin{array}{l}\text { Collector } \\
\& \text { Col\# }\end{array}$} & \multicolumn{5}{|c|}{$\begin{array}{l}\text { Inhibition diameter } \\
(\mathrm{mm}) \text {. Blank cells } \\
\text { indicate lack of } \\
\text { antibacterial activity }\end{array}$} & \multirow[t]{2}{*}{$\begin{array}{l}\text { Traditional } \\
\text { application }\end{array}$} \\
\hline & & & $\begin{array}{l}\bar{\delta} \\
\text { u } \\
\text { ن }\end{array}$ & 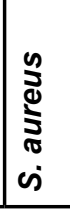 & 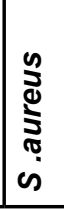 & 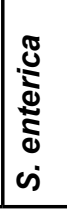 & 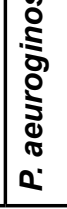 & \\
\hline \multicolumn{9}{|l|}{ Annonaceae } \\
\hline Annona muricata L. & Guanabana & ACR81 & & 11 & & & & In \\
\hline \multicolumn{9}{|l|}{ Apiaceae } \\
\hline Ammi visnaga (L.) Lam. cf. & Bisnaga & KMM566 & & & & & & $\mathrm{S}$ \\
\hline Apium graveolens $\mathrm{L}$. & Apio del campo & KMM439 & & 11 & & & & In \\
\hline Arracacia xanthorrhiza Bancr. & $\begin{array}{l}\text { Racacha } \\
\text { de zorro }\end{array}$ & KMM466 & & & & & & $\mathrm{S}$ \\
\hline Coriandrum sativum L. & Cilantro & KMM548 & & 12 & & & & $\mathrm{Dr}$ \\
\hline Foeniculum vulgare Mill. & Hinojo & ACR82 & & 10 & & & & In \\
\hline Foeniculum vulgare Mill. & Inojo & KMM409 & & & & & & $\ln$ \\
\hline $\begin{array}{l}\text { Niphogeton dissecta (Benth.) } \\
\text { J.F. Macbr. }\end{array}$ & Hornamo Toro & AKT1196 & 16 & 10 & & & & W \\
\hline Petroselinum crispum (Mill.) Fuss & Perejil & JULS225 & & 15 & & & & If \\
\hline \multicolumn{9}{|l|}{ Apocynaceae } \\
\hline $\begin{array}{l}\text { Mandevilla antennacea (A.DC.) } \\
\text { K. Schum. }\end{array}$ & Bejuco Colambo & GER236 & & 8 & & & & S \\
\hline Mandevilla cf. trianae Woodson & Bejuco Negro & ISA14 & 13 & 24 & & & & $\mathrm{~s}$ \\
\hline Mandevilla cf. trianae Woodson & Bejuco negro & AKT1221 & & & & & & $S$ \\
\hline Nerium oleander $\mathrm{L}$. & Laurel & ACR34 & & 13 & 11 & & & W \\
\hline $\begin{array}{l}\text { Thevetia peruviana (Pers.) } \\
\text { K. Schum. }\end{array}$ & Machil & KMM416 & & & & & & $\operatorname{Ar}$ \\
\hline \multicolumn{9}{|l|}{ Aquifoliaceae } \\
\hline Ilex guayusa Loes. & Gauyusa & KMM513 & & 14 & & & & $\ln$ \\
\hline \multicolumn{9}{|l|}{ Araceae } \\
\hline Anthurium sp. & Patecina negra & KMM486 & & & & & & $S$ \\
\hline \multicolumn{9}{|l|}{ Araliaceae } \\
\hline Hydrocotyle globiflora Ruiz. \& Pav. & Sombrero & KMM467 & & & & & & K \\
\hline Oreopanax eriocephalus Harms & Maqui Maqui & KMM445 & & & & & & If \\
\hline Oreopanax eriocephalus Harms & Maqui Maqui & JULS39 & & 8 & & & & If \\
\hline \multicolumn{9}{|l|}{ Aristolochiaceae } \\
\hline $\begin{array}{l}\text { Aristolochia cf. ruiziana (Klotzsch) } \\
\text { Duch. }\end{array}$ & $\begin{array}{l}\text { Bejuco Colambo } \\
\text { / Bejuco del Aire }\end{array}$ & $\begin{array}{l}\text { AKT1217/ } \\
\text { KMM563 } \\
\end{array}$ & & & & & & $S$ \\
\hline \multicolumn{9}{|l|}{ Asteraceae } \\
\hline $\begin{array}{l}\text { Acanthoxanthium } \\
\text { spinosum (L.) Fourr. }\end{array}$ & Juan Alonzo & AKT1127 & & & & & & $\ln$ \\
\hline
\end{tabular}




\begin{tabular}{|c|c|c|c|c|c|c|c|c|}
\hline \multirow[t]{2}{*}{$\begin{array}{l}\text { Plant Family } \\
\text { Species }\end{array}$} & \multirow[t]{2}{*}{ Common name } & \multirow[t]{2}{*}{$\begin{array}{l}\text { Collector } \\
\& \text { Col\# }\end{array}$} & \multicolumn{5}{|c|}{$\begin{array}{l}\text { Inhibition diameter } \\
(\mathrm{mm}) \text {. Blank cells } \\
\text { indicate lack of } \\
\text { antibacterial activity }\end{array}$} & \multirow[t]{2}{*}{$\begin{array}{l}\text { Traditional } \\
\text { application }\end{array}$} \\
\hline & & & $\begin{array}{l}\bar{\delta} \\
\text { uे } \\
\text { uं }\end{array}$ & 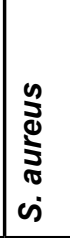 & 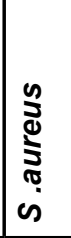 & 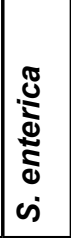 & 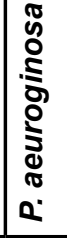 & \\
\hline Achillea millefolium $\mathrm{L}$. & Milenrama & $\begin{array}{l}\text { AKT1188/ } \\
\text { ACR139 }\end{array}$ & & & & & & Gastritis \\
\hline Achyrocline alata (Kunth) DC. & $\begin{array}{l}\text { Hierba de } \\
\text { Ishpingo }\end{array}$ & AKT1199 & & 10 & & & & $\mathrm{Ar}$ \\
\hline Achyrocline sp. & Espina de Hoja & KMM547 & & & & & & \\
\hline Ambrosia peruviana Willd. & $\begin{array}{l}\text { Marco o } \\
\text { Altamisa }\end{array}$ & ACR11 & 17 & 12 & & & & $\mathrm{Pi}$ \\
\hline Arctium lappa L. & Lampazo & GER227 & & 15 & & & & Urinary If \\
\hline Artemisia absinthium L. & Ajenjo & $\begin{array}{l}\text { KMM432/ } \\
\text { AKT1099 } \\
\end{array}$ & & & & & & $\begin{array}{l}\text { Menstrual } \\
\text { regulation }\end{array}$ \\
\hline $\begin{array}{l}\text { Baccharis genistelloides (Lam.) } \\
\text { Pers. }\end{array}$ & Karqueja & AKT1144 & & & & & & If \\
\hline Baccharis glutinosa Pers. & Pega Pega & KMM556 & & & & & & $\mathrm{Db}$ \\
\hline $\begin{array}{l}\text { Baccharis latifolia (Ruiz \& Pav.) } \\
\text { Pers. }\end{array}$ & Chilca Grande & ISA115 & & 12 & & & & $\mathrm{Ar}$ \\
\hline $\begin{array}{l}\text { Baccharis salicifolia (Ruiz. \& Pav.) } \\
\text { Pers. }\end{array}$ & Cedron & AKT1126 & & & & & & $S$ \\
\hline $\begin{array}{l}\text { Baccharis salicifolia (Ruiz. \& Pav.) } \\
\text { Pers }\end{array}$ & Chilco Hembra & GER125 & & 10 & & & & $S$ \\
\hline Baccharis sp & Chilca chica & KMM562 & & & & & & $\mathrm{Ar}$ \\
\hline Baccharis sp. & Chilca & KMM498 & & & 9 & & & $\mathrm{Ar}$ \\
\hline Baccharis cf. vaccinioides Kunth & $\begin{array}{l}\text { Sigueme } \\
\text { Sigueme }\end{array}$ & KMM565 & & & & & & $S$ \\
\hline Bidens pilosa L. & Amor seco & KMM427 & & & & & & $\mathrm{K}$ \\
\hline $\begin{array}{l}\text { Chersodoma deltoidea M.O. Dillon } \\
\text { \& Sagást. }\end{array}$ & Arquitecta & $\begin{array}{l}\text { ACR46/ } \\
\text { KMM446 } \\
\end{array}$ & & & & & & $S$ \\
\hline Chromolaena sp. & Asma chilca & ACR113 & & & & & & As \\
\hline Chromolaena sp & Asma chilca & KMM555 & & & & & & As \\
\hline $\begin{array}{l}\text { Chuquiraga spinosa Less. } \\
\text { ssp. humanpita C. Ezcurra }\end{array}$ & Huaman pinta & KMM434 & & & & & & $\ln$ \\
\hline Chuquiraga weberbaueri Tovar & Amaro & $\begin{array}{l}\text { KMM551/ } \\
\text { ACR85 }\end{array}$ & & & 10 & & & $\mathrm{Br}$ \\
\hline Cynara cardunculus L. & Alcachofa & KMM414 & & 14 & & & & $\mathrm{BI}$ \\
\hline $\begin{array}{l}\text { Diplostephium sagasteguii } \\
\text { Cuatrec. }\end{array}$ & Gato Simuro & $\begin{array}{l}\text { ACR124,153/ } \\
\text { AKT1145, } \\
\text { 1192/KMM478 }\end{array}$ & & 13 & & & & $\mathrm{~S}$ \\
\hline Eupatorium cf. gayanum Wedd. & Asma chilca & KMM555 & & & & & & As \\
\hline Flaveria bidentis (L.) Kuntze & Mata gusanos & KMM412 & & 9 & & & & $\mathrm{Br}$ \\
\hline
\end{tabular}


Bussmann et al. - Proving that Traditional Knowledge Works: The antibacterial activity of Northern Peruvian medicinal plants

\begin{tabular}{|c|c|c|c|c|c|c|c|c|}
\hline \multirow[t]{2}{*}{$\begin{array}{l}\text { Plant Family } \\
\text { Species }\end{array}$} & \multirow[t]{2}{*}{ Common name } & \multirow[t]{2}{*}{$\begin{array}{l}\text { Collector } \\
\& \text { Col\# }\end{array}$} & \multicolumn{5}{|c|}{$\begin{array}{l}\text { Inhibition diameter } \\
(\mathrm{mm}) \text {. Blank cells } \\
\text { indicate lack of } \\
\text { antibacterial activity }\end{array}$} & \multirow[t]{2}{*}{$\begin{array}{l}\text { Traditional } \\
\text { application }\end{array}$} \\
\hline & & & $\begin{array}{l}\text { ठे } \\
\text { 山ं }\end{array}$ & 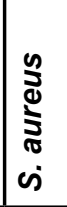 & 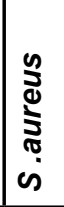 & 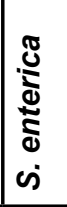 & 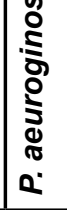 & \\
\hline Gnaphalium americanum Mill. & Lechugilla & $\begin{array}{l}\text { ACR41/ } \\
\text { KMM3933 }\end{array}$ & & 9 & & & & $\mathrm{Db}$ \\
\hline $\begin{array}{l}\text { Loricaria cf. ferruginea } \\
\text { (Ruiz \& Pav.) Wedd. }\end{array}$ & Pata de Gallina & $\begin{array}{l}\text { ACR63/ } \\
\text { AKT1174 }\end{array}$ & & 15 & & & & $S$ \\
\hline Loricaria pauciflora Cuatrec. & Palma & KMM473 & 9 & & & & & $S$ \\
\hline Loricaria sp. & Palma Bendita & ACR182 & & 8 & & & & $S$ \\
\hline Matricaria frigidum (Kunth) Kunth. & \begin{tabular}{|l|}
$\begin{array}{l}\text { Lavanda (la } \\
\text { banda) }\end{array}$ \\
\end{tabular} & AKT1175 & & & & & & $\ln$ \\
\hline Matricaria recutita L. & Manzanilla & ACR6 & & & & & & W \\
\hline $\begin{array}{l}\text { Munnozia lyrata (A. Gray) H. Rob. } \\
\text { \& Brettell }\end{array}$ & Caniahuanga & KMM519 & & & & & & $S$ \\
\hline Munnozia sp. & Salvia blanco & ACR148 & & & & & & $S$ \\
\hline $\begin{array}{l}\text { Onoseris odorata (D. Don) } \\
\text { Hook. \& Arn. }\end{array}$ & Hierba Aguila & ACR150 & & 7 & & & & $N$ \\
\hline $\begin{array}{l}\text { Oritrophium peruvianum (Lam.) } \\
\text { Cuatrec. }\end{array}$ & Huamanripa & JULS58 & & 14 & & & & Pneumonia \\
\hline $\begin{array}{l}\text { Perezia multiflora (Bonpl.) } \\
\text { Less. }\end{array}$ & Escorsonera & $\begin{array}{l}\text { KMM535/ } \\
\text { AKT1153 }\end{array}$ & & & & & & As \\
\hline Picrosia cf. longifolia D. Don. & Achicoria & \begin{tabular}{|l|} 
KMM436,540/ \\
ACR29, 39 \\
\end{tabular} & & & & & & $\mathrm{Bl}$ \\
\hline $\begin{array}{l}\text { Porophyllum ruderale (Jacq.) } \\
\text { Cass. }\end{array}$ & $\begin{array}{l}\text { Hierba de } \\
\text { Gallinazo } \\
\end{array}$ & KMM515 & & 23 & & & & $S$ \\
\hline $\begin{array}{l}\text { Pseudogynoxys cordifolia } \\
\text { (Cass.) Cabrera }\end{array}$ & Hierba San Juan & AKT1168 & & 8 & & & & $S$ \\
\hline $\begin{array}{l}\text { Schkuhria pinnata (Lam.) Kuntze } \\
\text { ex Thell. }\end{array}$ & Encanchallacha & ACR17 & 12 & & & & & Urinary If \\
\hline $\begin{array}{l}\text { Senecio canescens (Humb. } \\
\text { \& Bonpl.) Cuatrec. }\end{array}$ & Vira Vira & ACR44 & & 8 & & & & $\mathrm{Br}$ \\
\hline Senecio cf. tephrosioides Turcz. & Huamanripa & ACR65 & & & & & & As, Br \\
\hline Senecio chionogeton Wedd. & $\begin{array}{l}\text { Hornamo Leon } \\
\text { Amarillo }\end{array}$ & GER60 & 13 & 18 & & & & $\ln$ \\
\hline $\begin{array}{l}\text { Senecio cf. hypsiandinus } \\
\text { Cuatrec. }\end{array}$ & Ornama blanco & KMM523 & & & & & & $S$ \\
\hline Senecio sp. & Huamanripa & KMM449 & & 10 & & & & As, $\mathrm{Br}$ \\
\hline Senecio sp. & Ornamo & KMM480 & & & & & & $s$ \\
\hline Senecio sp. & Ornamo tigre & AKT1158 & & & & & & $S$ \\
\hline $\begin{array}{l}\text { Smallanthus sonchifolius } \\
\text { (Poepp. \& Endl.) H. Rob. }\end{array}$ & Yacon & ACR197 & & & & & & $\mathrm{Db}$, Prostate \\
\hline
\end{tabular}




\begin{tabular}{|c|c|c|c|c|c|c|c|c|}
\hline \multirow[t]{2}{*}{$\begin{array}{l}\text { Plant Family } \\
\text { Species }\end{array}$} & \multirow[t]{2}{*}{ Common name } & \multirow[t]{2}{*}{$\begin{array}{l}\text { Collector } \\
\& \text { Col\# }\end{array}$} & \multicolumn{5}{|c|}{$\begin{array}{l}\text { Inhibition diameter } \\
(\mathrm{mm}) \text {. Blank cells } \\
\text { indicate lack of } \\
\text { antibacterial activity }\end{array}$} & \multirow[t]{2}{*}{$\begin{array}{l}\text { Traditional } \\
\text { application }\end{array}$} \\
\hline & & & 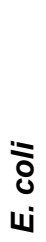 & 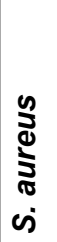 & 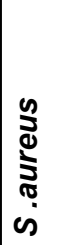 & 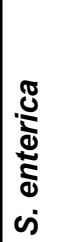 & 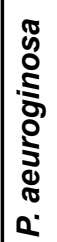 & \\
\hline Sonchus oleraceus L. & Serraja & KMM438 & & & & & & $\begin{array}{l}\text { High blood } \\
\text { pressure }\end{array}$ \\
\hline Stevia sp. & Pastomiel & KMM588 & & & & & & Cholesterol \\
\hline Tagetes elliptica Sm. & $\begin{array}{l}\text { Culantrillo } \\
\text { Serrano }\end{array}$ & GER184 & & 13 & & & & $\mathrm{Br}$ \\
\hline Tagetes erecta L. & Flor de Muerto & JULS156 & & 20 & & & & $\ln$ \\
\hline Tagetes filifolia Lag. & Anis & KMM524 & & & & & & $\mathrm{Dr}$ \\
\hline $\begin{array}{l}\text { Tanacetum parthenium } \\
\text { (L.) Sch. Bip. }\end{array}$ & $\begin{array}{l}\text { Manzanilla } \\
\text { de campo }\end{array}$ & ACR14 & & & & & & $S$ \\
\hline Taraxacum officinale F.H. Wigg. & Amargon & JULS150 & & 20 & & & & In \\
\hline Tessaria integrifolia Ruiz. \& Pav. & Pajaro bobo & KMM465 & & & & & & $\ln$ \\
\hline $\begin{array}{l}\text { Trixis cf. cacalioides (Kunth) } \\
\text { D. Don }\end{array}$ & Añasquero & KMM497 & & & & & & $\mathrm{S}$ \\
\hline Verbesina sp. & Sabadilla & ACR154 & & 13 & & & & W \\
\hline Werneria nubigena Kunth & $\begin{array}{l}\text { Hierba de } \\
\text { halago }\end{array}$ & ACR205 & & & & & & $\mathrm{S}$ \\
\hline \multirow[t]{5}{*}{ Werneria sp. } & & AKT1178 & & & & & & $\mathrm{S}$ \\
\hline & Churguis & KMM405 & & & & & & $S$ \\
\hline & Hierba de Amor & KMM522 & & & & & & $S$ \\
\hline & Miscichilca & KMM490 & & & & & & $S$ \\
\hline & Olvido & KMM538 & & & & & & $S$ \\
\hline \multicolumn{9}{|l|}{ Balanophoraceae } \\
\hline Corynaea crassa Hook. f. & Huanarpo & ACR130 & & & & & & Fertility \\
\hline Corynaea crassa Hook. f. & Huanarpo & AKT1169 & & 11 & & & & Fertility \\
\hline \multicolumn{9}{|l|}{ Berberidaceae } \\
\hline Berberis buceronis J.F. Macbr. & Palo Amarillo & KMM573 & 8 & 21 & & & & Hepatitis \\
\hline \multicolumn{9}{|l|}{ Betulaceae } \\
\hline Alnus acuminata Kunth & Aliso & KMM418 & & & 10 & & & W \\
\hline Alnus acuminata Kunth & Aliso & ACR75 & & 14 & & & & W \\
\hline \multicolumn{9}{|l|}{ Bignoniaceae } \\
\hline Crescentia cujete L. & Turuma & AKT1157 & 9 & & & & & $\begin{array}{l}\text { Healing of } \\
\text { belly button }\end{array}$ \\
\hline Cydista aequinoctialis (L.) Miers & Bejuco Amarillo & ISA6 & 7 & 21 & & & & In from sorcery \\
\hline $\begin{array}{l}\text { Jacaranda acutifolia } \\
\text { Humb. \& Bonpl. }\end{array}$ & Arabisco & ACR89 & 7 & 16 & & & & $\mathrm{Br}$ \\
\hline
\end{tabular}


Bussmann et al. - Proving that Traditional Knowledge Works: The antibacterial activity of Northern Peruvian medicinal plants

\begin{tabular}{|c|c|c|c|c|c|c|c|c|}
\hline \multirow[t]{2}{*}{$\begin{array}{l}\text { Plant Family } \\
\text { Species }\end{array}$} & \multirow[t]{2}{*}{ Common name } & \multirow[t]{2}{*}{$\begin{array}{l}\text { Collector } \\
\& \text { Col\# }\end{array}$} & \multicolumn{5}{|c|}{$\begin{array}{l}\text { Inhibition diameter } \\
(\mathrm{mm}) \text {. Blank cells } \\
\text { indicate lack of } \\
\text { antibacterial activity }\end{array}$} & \multirow[t]{2}{*}{$\begin{array}{l}\text { Traditional } \\
\text { application }\end{array}$} \\
\hline & & & $\begin{array}{l}\overline{\text { ò }} \\
\text { uं }\end{array}$ & 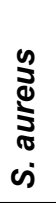 & 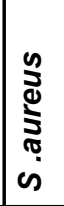 & 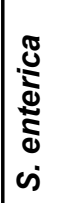 & 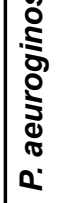 & \\
\hline \multicolumn{9}{|l|}{ Bixaceae } \\
\hline Bixa orellana L. & Achiote & KMM429 & & 11 & & & & $\mathrm{~K}$ \\
\hline \multicolumn{9}{|l|}{ Boraginaceae } \\
\hline Borago officinalis L. & Borraja & ACR9 & & & & & & $\mathrm{BI}$ \\
\hline $\begin{array}{l}\text { Cordia alliodora (Ruiz. \& Pav.) } \\
\text { Oken. }\end{array}$ & Ajo Sacha & KMM489 & & 13 & & & & $\mathrm{Br}$ \\
\hline Cordia lutea Lam. & Obero & AKT1114 & & & & & & K \\
\hline Heliotropium curassavicum L. & Alacran & ACR57 & & & & & & $S$ \\
\hline $\begin{array}{l}\text { Tiquilia paronychioides (Phil.) } \\
\text { A.T. Richardson }\end{array}$ & Flor de arena & KMM406 & & 12 & & & & In \\
\hline \multicolumn{9}{|l|}{ Brassicaceae } \\
\hline Brassica oleracea L. & Col & JULS147 & & 11 & & & & Gallstones \\
\hline Capsella bursa-pastoris (L.) Medik. & Bolsa pastor & KMM451 & & & & & & $\mathrm{K}$ \\
\hline $\begin{array}{l}\text { Rorippa nasturtium- } \\
\text { aquaticum (L.) Hayek }\end{array}$ & Berros & $\begin{array}{l}\text { ACR94/ } \\
\text { AKT1163 }\end{array}$ & & 7 & & & & $\mathrm{Br}$ \\
\hline \multicolumn{9}{|l|}{ Bromeliaceae } \\
\hline Puya hamata L.B. Sm. & $\begin{array}{l}\text { Hierba del } \\
\text { carnero }\end{array}$ & KMM520 & & & & & & $S$ \\
\hline Tillandsia cf. cacticola L.B. Sm. & Siempre viva & ACR183 & & & & & & $S$ \\
\hline Tillandsia sp. & $\begin{array}{l}\text { Brocamedia/ } \\
\text { Brocamelia }\end{array}$ & KMM571 & & & & & & $S$ \\
\hline \multicolumn{9}{|l|}{ Burseraceae } \\
\hline $\begin{array}{l}\text { Bursera graveolens (Kunth) } \\
\text { Triana \& Planch. }\end{array}$ & Palo Santo & ACR132 & & & & & & $\mathrm{Br}$ \\
\hline Commiphora sp. & Mirra & KMM579 & & & & & & $S$ \\
\hline \multicolumn{9}{|l|}{ Cactaceae } \\
\hline $\begin{array}{l}\text { Echinopsis pachanoi (Britton \& } \\
\text { Rose) H. Friedrich \& G.D. Rowley }\end{array}$ & San Pedro & ACR95 & & & & & & $\begin{array}{l}\text { W caused by } \\
\text { witchcraft }\end{array}$ \\
\hline \multirow[t]{2}{*}{ Opuntia ficus-indica (L.) Mill. } & Tuna & AKT1220 & 21 & & & & & $\mathrm{Db}$ \\
\hline & Orillo de Brujo & ACR93 & & & & & & $S$ \\
\hline \multicolumn{9}{|l|}{ Calceolariaceae } \\
\hline Calceolaria percaespitosa Wooden & Canillahuanga & AKT1195 & & & & & & $S$ \\
\hline \multicolumn{9}{|l|}{ Calophyllaceae } \\
\hline Mammea americana L. & Mamey & KMM568 & & & & & & $\mathrm{Dr}$ \\
\hline \multicolumn{9}{|l|}{ Campanulaceae } \\
\hline Centropogon articulatus Drake & Conchalalay & EHCHL119 & & 6 & & & & S \\
\hline
\end{tabular}




\begin{tabular}{|c|c|c|c|c|c|c|c|c|}
\hline \multirow[t]{2}{*}{$\begin{array}{l}\text { Plant Family } \\
\text { Species }\end{array}$} & \multirow[t]{2}{*}{ Common name } & \multirow[t]{2}{*}{$\begin{array}{l}\text { Collector } \\
\& \text { Col\# }\end{array}$} & \multicolumn{5}{|c|}{$\begin{array}{l}\text { Inhibition diameter } \\
(\mathrm{mm}) \text {. Blank cells } \\
\text { indicate lack of } \\
\text { antibacterial activity }\end{array}$} & \multirow[t]{2}{*}{$\begin{array}{l}\text { Traditional } \\
\text { application }\end{array}$} \\
\hline & & & $\mid \begin{array}{l}\bar{\delta} \\
\text { uे }\end{array}$ & 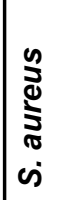 & 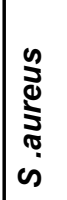 & 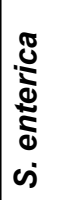 & 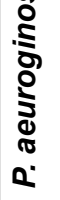 & \\
\hline Centropogon sp. & Canchalagua & $\begin{array}{l}\text { KMM536/ } \\
\text { ACR17 }\end{array}$ & & & & & & $S$ \\
\hline Centropogon sp. & Canchalaly & ACR147 & & & & & & $S$ \\
\hline Centropogon sp. & Trinoso & KMM545 & 16 & 16 & & & & Skin problems \\
\hline Lobelia decurrens Cav. & Contoya & $\begin{array}{l}\text { KMM443/ } \\
\text { ACR157 }\end{array}$ & & & & & & $S$ \\
\hline \multicolumn{9}{|l|}{ Capparidaceae } \\
\hline Capparis crotonoides Kunth & Simura & KMM586 & & & & & & $\mathrm{Ar}$ \\
\hline Capparis scabrida Kunth & Zapote & KMM554 & & & & & & In \\
\hline \multicolumn{9}{|l|}{ Caprifoliaceae } \\
\hline cf. Belonanthus & Baton de Oro & $\begin{array}{l}\text { ACR127/ } \\
\text { KMM494 }\end{array}$ & & & & & & $S$ \\
\hline Dipsacus fullonum $\mathrm{L}$. & Cardo Santo & EHCHL90 & & 12 & & & & $\mathrm{Db}$ \\
\hline $\begin{array}{l}\text { Lonicera cf. japonica Thunb. } \\
\text { ex Murray }\end{array}$ & Madre de Selva & KMM390 & & & & & & Depression \\
\hline $\begin{array}{l}\text { Lonicera japonica Thunb. } \\
\text { ex Murray }\end{array}$ & Madre Selva & JULS28 & & 9 & & & & Depression \\
\hline $\begin{array}{l}\text { Phyllactis rigida (Ruiz \& Pav.) } \\
\text { Pers. }\end{array}$ & Estrella & KMM481 & & 15 & & & & $\mathrm{~S}$ \\
\hline $\begin{array}{l}\text { Phyllactis rigida (Ruiz \& Pav.) } \\
\text { Pers. }\end{array}$ & $\begin{array}{l}\text { Valeriana } \\
\text { estrella }\end{array}$ & AKT1117 & & & & & & S \\
\hline Sambucus peruviana Kunth & Sauco & $\begin{array}{l}\text { ACR66/ } \\
\text { AKT1103 }\end{array}$ & & & & & & $\begin{array}{l}\text { Br, Yellow } \\
\text { Fever }\end{array}$ \\
\hline Sambucus peruviana Kunth & Sauco & KMM539 & & 6 & & & & $\begin{array}{l}\text { Br, Yellow } \\
\text { Fever }\end{array}$ \\
\hline Scabiosa atropurpurea L. & Ambarilla & ACR158 & & 10 & & & & $\mathrm{Br}$ \\
\hline Valeriana cf. bonplandiana Wedd. & Fortuna & ACR181 & & & & & & $S$ \\
\hline cf. Valeriana plantaginea Kunth & $\begin{array}{l}\text { Ornamo } \\
\text { caballero }\end{array}$ & ACR120 & & 9 & & & & $S$ \\
\hline Valeriana sp. & $\begin{array}{l}\text { Hornamo del } \\
\text { Caballo }\end{array}$ & AKT1140 & & & & & & S \\
\hline Valeriana sp. & Ornamo & AKT1141 & & & 11 & & & $\mathrm{~S}$ \\
\hline Valeriana sp. & Valeriana & AKT1213 & & 10 & & & & $\mathrm{~S}$ \\
\hline Valeriana sp. & $\begin{array}{l}\text { Valeriana } \\
\text { Delgada }\end{array}$ & KMM394 & & 12 & & & & $\mathrm{~S}$ \\
\hline Valeriana sp. & Valeriana gruesa & KMM396 & & 13 & 13 & & & $\mathrm{~S}$ \\
\hline
\end{tabular}


Bussmann et al. - Proving that Traditional Knowledge Works: The antibacterial activity of Northern Peruvian medicinal plants

\begin{tabular}{|c|c|c|c|c|c|c|c|c|}
\hline \multirow[t]{2}{*}{$\begin{array}{l}\text { Plant Family } \\
\text { Species }\end{array}$} & \multirow[t]{2}{*}{ Common name } & \multirow[t]{2}{*}{$\begin{array}{l}\text { Collector } \\
\& \text { Col\# }\end{array}$} & \multicolumn{5}{|c|}{$\begin{array}{l}\text { Inhibition diameter } \\
(\mathrm{mm}) \text {. Blank cells } \\
\text { indicate lack of } \\
\text { antibacterial activity }\end{array}$} & \multirow[t]{2}{*}{$\begin{array}{l}\text { Traditional } \\
\text { application }\end{array}$} \\
\hline & & & $\begin{array}{l}\text { 亏े } \\
\text { uं }\end{array}$ & 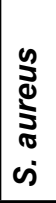 & 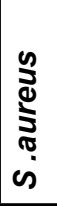 & 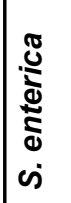 & 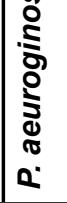 & \\
\hline \multicolumn{9}{|l|}{ Caryophyllaceae } \\
\hline Dianthus caryophyllus L. & Claveles & AKT1125 & & & & & & Depression \\
\hline \multicolumn{9}{|l|}{ Chloranthaceae } \\
\hline $\begin{array}{l}\text { Hedyosmum racemosum } \\
\text { (Ruiz. \& Pav.) G. Don. }\end{array}$ & Asancsito & KMM505 & & 18 & & & & $\mathrm{Br}$ \\
\hline \multicolumn{9}{|l|}{ Clethraceae } \\
\hline Clethra castaneifolia Meisn. & $\begin{array}{l}\text { Hierba del } \\
\text { olvido }\end{array}$ & KMM549 & & 11 & & & & $S$ \\
\hline Clethra castaneifolia Meisn. & Olvido & ACR109 & 8 & & & & & $S$ \\
\hline \multicolumn{9}{|l|}{ Clusiaceae } \\
\hline Clusia minor L. & Chusgon & JULS280 & & 16 & & & & $\mathrm{~N}$ \\
\hline Hypericum laricifolium Juss. & Chinchango & $\begin{array}{l}\text { AKT1912/ } \\
\text { KMM533 }\end{array}$ & & & & & & $S$ \\
\hline Hypericum laricifolium Juss. & Pachuli & AKT1172 & & 12 & & & & $\mathrm{~S}$ \\
\hline Hypericum silenoides Juss. & Cintaura & $\begin{array}{l}\text { AKT1154/ } \\
\text { KMM387/ } \\
\text { ACR152 }\end{array}$ & & 13 & & & & $\mathrm{Dr}$ \\
\hline \multicolumn{9}{|l|}{ Convolvulaceae } \\
\hline Cuscuta foetida Kunth & Pelo de duende & ACR98 & & & & & & Goiter \\
\hline $\begin{array}{l}\text { Ipomoea pauciflora M. Martens } \\
\text { \& Galeotti }\end{array}$ & Huanarpo & GER222 & & 16 & & & & Cold \\
\hline \multicolumn{9}{|l|}{ Crassulaceae } \\
\hline Echeveria peruviana Meyen & Pin Pin & $\begin{array}{l}\text { ACR169/ } \\
\text { AKT1165 } \\
\end{array}$ & & & & & & $\mathrm{K}$ \\
\hline \multicolumn{9}{|l|}{ Cucurbitaceae } \\
\hline Sicana odorifera (Vell.) Naudin & Cecana & ACR96 & & 11 & & & & $S$ \\
\hline \multicolumn{9}{|l|}{ Cupressaceae } \\
\hline Cupressus sempervirens L. & Pino silvestre & $\begin{array}{l}\text { AKT1181/ } \\
\text { KMM506 } \\
\end{array}$ & & & & & & Hemorrhage \\
\hline \multicolumn{9}{|l|}{ Cyperaceae } \\
\hline Oreobolus goeppingeri Suess. & $\begin{array}{l}\text { Hierba del } \\
\text { Carpintero }\end{array}$ & $\begin{array}{l}\text { KMM493/ } \\
\text { ACR126 } \\
\end{array}$ & & 12 & & & & $S$ \\
\hline $\begin{array}{l}\text { Scirpus californicus Steud. ssp. } \\
\text { tatora (Kunth) T. Koyama }\end{array}$ & Totora & ACR204 & & & & & & Fever \\
\hline \multicolumn{9}{|l|}{ Dioscoreaceae } \\
\hline Dioscorea sp. & $\begin{array}{l}\text { Papa de Buenas } \\
\text { Tardes }\end{array}$ & KMM462 & & & & & & $\mathrm{K}$ \\
\hline
\end{tabular}




\begin{tabular}{|c|c|c|c|c|c|c|c|c|}
\hline \multirow[t]{2}{*}{$\begin{array}{l}\text { Plant Family } \\
\text { Species }\end{array}$} & \multirow[t]{2}{*}{ Common name } & \multirow[t]{2}{*}{$\begin{array}{l}\text { Collector } \\
\& \text { Col\# }\end{array}$} & \multicolumn{5}{|c|}{$\begin{array}{l}\text { Inhibition diameter } \\
\text { ( } \mathrm{mm}) \text {. Blank cells } \\
\text { indicate lack of } \\
\text { antibacterial activity }\end{array}$} & \multirow[t]{2}{*}{$\begin{array}{l}\text { Traditional } \\
\text { application }\end{array}$} \\
\hline & & & $\begin{array}{l}\text { ठे } \\
\text { யं }\end{array}$ & 先 & 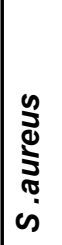 & 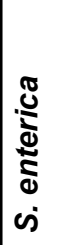 & 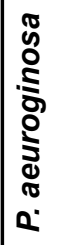 & \\
\hline Dioscorea tambillensis R. Kunth & Papa semintona & KMM583 & & & & & & K \\
\hline Dioscorea tambillensis R. Kunth & Papa semitona & KMM583 & & 12 & & & & $\mathrm{~K}$ \\
\hline Dioscorea trifida L.f. & Papa madre & KMM503 & 11 & 30 & & & 11 & W, Cancer \\
\hline \multicolumn{9}{|l|}{ Ephedraceae } \\
\hline $\begin{array}{l}\text { Ephedra americana Humb. } \\
\text { \& Bonpl. ex Willd. }\end{array}$ & Diego Lopez & AKT1159 & & & & & & Fractures \\
\hline $\begin{array}{l}\text { Ephedra americana Humb. } \\
\text { \& Bonpl. ex Willd. }\end{array}$ & Diego Lopez & KMM511 & 8 & 22 & & & & Fractures \\
\hline \multicolumn{9}{|l|}{ Equisetaceae } \\
\hline Equisetum bogotense Kunth & Cola de caballo & ACR1 & & 9 & & & & W \\
\hline \multicolumn{9}{|l|}{ Ericaceae } \\
\hline Bejaria aestuans Mutis ex L. & $\begin{array}{l}\text { Hierba de la } \\
\text { postema }\end{array}$ & KMM527 & & 12 & & & & In \\
\hline Bejaria aestuans Mutis ex L. & $\begin{array}{l}\text { Purunrosa/ } \\
\text { FlorPostema }\end{array}$ & AKT1109 & & & & & & In \\
\hline Gaultheria erecta Vent. & Mullaca & $\begin{array}{l}\text { KMM472/ } \\
\text { JULS288 }\end{array}$ & & 13 & 11 & & & $\mathrm{Br}$ \\
\hline Gaultheria reticulata Kunth & Maike & KMM531 & & 9 & & & & $\operatorname{Ar}$ \\
\hline \multicolumn{9}{|l|}{ Escalloniaceae } \\
\hline $\begin{array}{l}\text { Escallonia pendula (Ruiz \& Pav.) } \\
\text { Pers. }\end{array}$ & Chuque & ISA23 & & 18 & & & & $\mathrm{Ar}$ \\
\hline \multicolumn{9}{|l|}{ Euphorbiaceae } \\
\hline Acalypha mandonii Müll. Arg. & Chilca Dulce & RBU/PL294 & & 11 & & & & Liver In \\
\hline Hura crepitans L. & Habilla & AKT1225 & & & & & & $\mathrm{S}$ \\
\hline \multirow[t]{2}{*}{ Jatropha macrantha Müll. Arg. } & Piñones & $\begin{array}{l}\text { AKT1230/ } \\
\text { KMM487 } \\
\end{array}$ & & & & & & S \\
\hline & Chilca Dulce & ACR151 & & & & & & $\mathrm{BI}$ \\
\hline \multicolumn{9}{|l|}{ Fabaceae } \\
\hline $\begin{array}{l}\text { Acacia macracantha Humb. } \\
\text { \& Bonpl. ex Willd. }\end{array}$ & Faique & JULS172 & & 15 & & & & W \\
\hline Caesalpinia paipai Ruiz \& Pav. & Pai pai & $\begin{array}{l}\text { KMM581/ } \\
\text { GER40 }\end{array}$ & & 14 & 20 & & & W \\
\hline $\begin{array}{l}\text { Caesalpinia spinosa } \\
\text { (Molina) Kuntze }\end{array}$ & Taya or Tara & ACR111 & 10 & 23 & & 10 & 11 & $\begin{array}{l}\text { Tonsilitis, } \\
\text { Skin In, W }\end{array}$ \\
\hline Cajanus cajan (L.) Huth & Chibato & ACR10 & & & & & & $S$ \\
\hline Cassia fistula L. & Caña Fistula & RBU/PL386 & & 12 & & & & $\mathrm{~N}$ \\
\hline
\end{tabular}


Bussmann et al. - Proving that Traditional Knowledge Works: The antibacterial activity of Northern Peruvian medicinal plants

\begin{tabular}{|c|c|c|c|c|c|c|c|c|}
\hline \multirow[t]{2}{*}{$\begin{array}{l}\text { Plant Family } \\
\text { Species }\end{array}$} & \multirow[t]{2}{*}{ Common name } & \multirow[t]{2}{*}{$\begin{array}{l}\text { Collector } \\
\text { \& Col\# }\end{array}$} & \multicolumn{5}{|c|}{$\begin{array}{l}\text { Inhibition diameter } \\
(\mathrm{mm}) \text {. Blank cells } \\
\text { indicate lack of } \\
\text { antibacterial activity }\end{array}$} & \multirow[t]{2}{*}{$\begin{array}{l}\text { Traditional } \\
\text { application }\end{array}$} \\
\hline & & & $\begin{array}{l}\text { ¿े } \\
\text { 山ं }\end{array}$ & 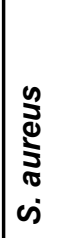 & 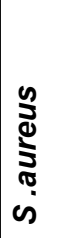 & 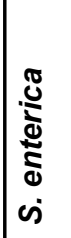 & 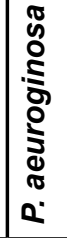 & \\
\hline Cassia fistula L. & Ceiña Fistala & ACR88 & & & & & & $\mathrm{N}$ \\
\hline $\begin{array}{l}\text { Desmodium molliculum } \\
\text { (Kunth) DC. }\end{array}$ & Manda yupa & $\begin{array}{l}\text { AKT1162/ } \\
\text { KMM392 }\end{array}$ & & 8 & & & & W \\
\hline $\begin{array}{l}\text { Leucaena leucocephala } \\
\text { (Lam.) De Wit }\end{array}$ & Arabisca & JULS104 & 7 & & & & & W \\
\hline Lupinus mutabilis Sweet & Chochos & ACR102 & & & & & & Nutrition \\
\hline Medicago sativa L. & Trebol de agua & \begin{tabular}{|l} 
KMM463/ \\
ACR51 \\
\end{tabular} & 10 & 7 & & & & $\mathrm{Br}$ \\
\hline Melilotus albus Medik. & Fenogreco & KMM459 & & & & & & Ifs \\
\hline $\begin{array}{l}\text { Mimosa albida Humb. \& Bonpl. } \\
\text { ex Willd. }\end{array}$ & Tapa Tapa & ACR79 & & & & & & $S$ \\
\hline $\begin{array}{l}\text { Mimosa albida Humb. \& Bonpl. } \\
\text { ex Willd. }\end{array}$ & Tutapure & $\begin{array}{l}\text { KMM560/ } \\
\text { ACR190/ } \\
\text { AKT1118 }\end{array}$ & & 12 & & & & W \\
\hline Myroxylon balsamum (L.) Harms & Quina Quina & JULS287 & & 12 & & & & $\mathrm{Br}$ \\
\hline Myroxylon balsamum (L.) Harms & Quina Quina & AKT1223 & & & & & & $\mathrm{Br}$ \\
\hline $\begin{array}{l}\text { Prosopis pallida (Humb. \& } \\
\text { Bonpl. ex Willd.) Kunth }\end{array}$ & Algarrobina & ACR203 & & 15 & & & & $\mathrm{Br}$ \\
\hline Senna cf. bicapsularis (L.) Roxb. & Alcaparilla & ACR194 & & 15 & & & & $\mathrm{BI}$ \\
\hline $\begin{array}{l}\text { Senna monilifera H.S. Irwin } \\
\text { \& Barnaby }\end{array}$ & Sen & $\begin{array}{l}\text { KMM470/ } \\
\text { AKT1112 }\end{array}$ & & & & & & Purgative \\
\hline $\begin{array}{l}\text { Senna monilifera H.S. Irwin } \\
\text { \& Barnaby }\end{array}$ & Sen & KMM470 & & 17 & & & & Purgative \\
\hline Spartium junceum L. & Ratanica & $\begin{array}{l}\text { AKT1222/ } \\
\text { KMM407 }\end{array}$ & & 14 & & & & $\mathrm{BI}$ \\
\hline Spartium junceum L. & Retama & ACR108 & & & & & & $\mathrm{BI}$ \\
\hline Trifolium repens $\mathrm{L}$. & Trebol & $\begin{array}{l}\text { AKT1194/ } \\
\text { KMM577 }\end{array}$ & & & & & & $\mathrm{K}$ \\
\hline \multicolumn{9}{|l|}{ Gentianaceae } \\
\hline Coutoubea ramosa Aubl. & Genciana & GER173 & & 12 & & & & W \\
\hline Gentiana sedifolia Kunth & $\begin{array}{l}\text { Horma de } \\
\text { amarilla }\end{array}$ & ACR92 & & & & & & $S$ \\
\hline $\begin{array}{l}\text { Gentianella bicolor (Wedd.) } \\
\text { Fabris ex J.S. Pringle }\end{array}$ & Amargon & ACR156 & & & & & & $\mathrm{Ar}$ \\
\hline $\begin{array}{l}\text { Gentianella bicolor (Wedd.) } \\
\text { Fabris ex J.S. Pringle } \\
\end{array}$ & Corpusway & KMM526 & & 18 & & & & $\mathrm{Ar}$ \\
\hline $\begin{array}{l}\text { Gentianella brunneotincta } \\
\text { (Gilg.) J.S. Pringle }\end{array}$ & Yanga macha & KMM403 & & & & & & $\begin{array}{l}\text { Uterus If } \\
\text { after birth }\end{array}$ \\
\hline
\end{tabular}




\begin{tabular}{|c|c|c|c|c|c|c|c|c|}
\hline \multirow[t]{2}{*}{$\begin{array}{l}\text { Plant Family } \\
\text { Species }\end{array}$} & \multirow[t]{2}{*}{ Common name } & \multirow[t]{2}{*}{$\begin{array}{l}\text { Collector } \\
\& \text { Col\# }\end{array}$} & \multicolumn{5}{|c|}{$\begin{array}{l}\text { Inhibition diameter } \\
\text { ( } \mathrm{mm}) \text {. Blank cells } \\
\text { indicate lack of } \\
\text { antibacterial activity }\end{array}$} & \multirow[t]{2}{*}{$\begin{array}{l}\text { Traditional } \\
\text { application }\end{array}$} \\
\hline & & & 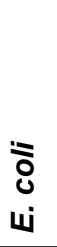 & 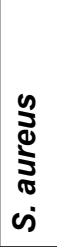 & 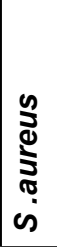 & 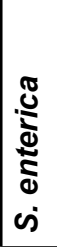 & 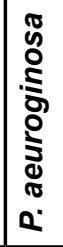 & \\
\hline $\begin{array}{l}\text { Gentianella crassicaulis } \\
\text { J.S. Pringle }\end{array}$ & Agagencia & $\begin{array}{l}\text { ACR20/ } \\
\text { KMM422 }\end{array}$ & & 13 & 12 & & & $\mathrm{Db}$ \\
\hline $\begin{array}{l}\text { Gentianella dianthoides (Kunth) } \\
\text { Fabris ex J.S. Pringle }\end{array}$ & Chagape & ACR155 & & 10 & & & & $\mathrm{Bl}$ \\
\hline $\begin{array}{l}\text { Gentianella dianthoides (Kunth) } \\
\text { Fabris ex J.S. Pringle }\end{array}$ & Genciana & KMM576 & & & & & & $\mathrm{BI}$ \\
\hline $\begin{array}{l}\text { Gentianella graminea } \\
\text { (Kunth) Fabris }\end{array}$ & Sumaran & AKT1164 & & & & & & $\mathrm{Bl}$ \\
\hline Gentianella sp. & $\begin{array}{l}\text { Hornamo } \\
\text { asmarillo }\end{array}$ & ACR92 & & & & & & $\mathrm{BI}$ \\
\hline \multicolumn{9}{|l|}{ Geraniaceae } \\
\hline $\begin{array}{l}\text { Erodium cicutarium (L.) } \\
\text { L'Hér. ex Aiton }\end{array}$ & Agujilla & AKT1171 & & & & & & $\mathrm{Br}$ \\
\hline $\begin{array}{l}\text { Erodium cicutarium (L.) } \\
\text { L'Hér. ex Aiton }\end{array}$ & Cachujillo & KMM578 & & 15 & & & & $\mathrm{Br}$ \\
\hline $\begin{array}{l}\text { Geranium ayavacense } \\
\text { Willd. ex Kunth }\end{array}$ & Pasuchaca & JULS48 & & 12 & & & & If \\
\hline $\begin{array}{l}\text { Geranium cf. ayavacense } \\
\text { Willd. ex Kunth }\end{array}$ & Pasuchaca & KMM401 & & & & & & If \\
\hline Geranium sessiliflorum Cav. & Pasuchaca & KMM400 & & 20 & 15 & & & If \\
\hline Geranium sessiliflorum Cav. & Pasuchaca & ACR38 & & 12 & & & & If \\
\hline $\begin{array}{l}\text { Pelargonium cf. odoratissimum } \\
\text { (L.) L'Hér. }\end{array}$ & Malva de Olor & ACR26 & & 8 & & & & $\mathrm{BI}$ \\
\hline \multicolumn{9}{|l|}{ Gigartinaceae } \\
\hline $\begin{array}{l}\text { Gigartina chamissoi (C. } \\
\text { Agardh) J. Agardh }\end{array}$ & Cochayuyo & AKT393, 1226 & & & & & & Cholesterol \\
\hline \multicolumn{9}{|l|}{ Iliciaceae } \\
\hline Illicium verum Hook. f. & Anis estrella & AKT1208 & & & & & & $\begin{array}{l}\text { Expel residues } \\
\text { from the } \\
\text { stomach of } \\
\text { newborns } \\
\end{array}$ \\
\hline \multicolumn{9}{|l|}{ Iridaceae } \\
\hline $\begin{array}{l}\text { Hesperoxiphion niveum (Ravenna) } \\
\text { Ravenna }\end{array}$ & $\begin{array}{l}\text { Hierba de } \\
\text { la justicia }\end{array}$ & $\begin{array}{l}\text { AKT1100/ } \\
\text { ACR45 }\end{array}$ & & & 9 & & & $\mathrm{~S}$ \\
\hline \multicolumn{9}{|c|}{ Juglandaceae } \\
\hline Juglans neotropica Diels & Nogales & $\begin{array}{l}\text { AKT1111/ } \\
\text { KMM435/ } \\
\text { ACR71 }\end{array}$ & & 11 & & & & W \\
\hline
\end{tabular}


Bussmann et al. - Proving that Traditional Knowledge Works: The antibacterial activity of Northern Peruvian medicinal plants

\begin{tabular}{|c|c|c|c|c|c|c|c|c|}
\hline \multirow[t]{2}{*}{$\begin{array}{l}\text { Plant Family } \\
\text { Species }\end{array}$} & \multirow[t]{2}{*}{ Common name } & \multirow[t]{2}{*}{$\begin{array}{l}\text { Collector } \\
\text { \& Col\# }\end{array}$} & \multicolumn{5}{|c|}{$\begin{array}{l}\text { Inhibition diameter } \\
(\mathrm{mm}) \text {. Blank cells } \\
\text { indicate lack of } \\
\text { antibacterial activity }\end{array}$} & \multirow[t]{2}{*}{$\begin{array}{l}\text { Traditional } \\
\text { application }\end{array}$} \\
\hline & & & $\begin{array}{l}\bar{\delta} \\
\text { แं }\end{array}$ & 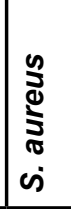 & 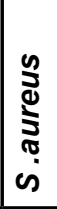 & 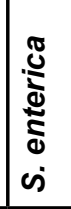 & 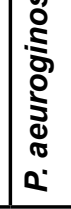 & \\
\hline \multicolumn{9}{|l|}{ Krameriaceae } \\
\hline $\begin{array}{l}\text { Krameria lappacea (Dombey) } \\
\text { H.M. Burdet \& B.B. Simpson }\end{array}$ & Retamia & ACR48 & 12 & 15 & & & & In \\
\hline \multicolumn{9}{|l|}{ Lamiaceae } \\
\hline $\begin{array}{l}\text { Clinopodium pulchellum } \\
\text { (Kunth) Govaerts }\end{array}$ & Panizara & ACR97 & & & & & & $S$ \\
\hline Hyptis sidifolia (L’Hér.) Briq. & Albaca serrana & ACR18 & & & 12 & & & Colic \\
\hline Hyptis sidifolia (L’Hér.) Briq. & \begin{tabular}{|l} 
Perroreya \\
\end{tabular} & ACR69, 18 & 10 & 13 & & & & Colic \\
\hline Marrubium vulgare $\mathrm{L}$. & $\begin{array}{l}\text { Cordon de } \\
\text { Muerto }\end{array}$ & KMM452 & & & & & & $S$ \\
\hline Melissa officinalis L. & Toronjil & ACR4 & & & & & & $\mathrm{N}$ \\
\hline Mentha X piperita L. & Poleo & JULS29 & & 6 & & & & Colic \\
\hline Mentha X piperita L. & Poleo & ACR68 & & & & & & Colic \\
\hline Mentha spicata L. & Menta & KMM453 & & 12 & & & & Anthelminthic \\
\hline $\begin{array}{l}\text { Minthostachys mollis (Kunth) } \\
\text { Griseb. }\end{array}$ & $\begin{array}{l}\text { Chancas de } \\
\text { muerto }\end{array}$ & AKT1142 & & & & & & Colic \\
\hline Ocimum basilicum L. & Albaca & $\begin{array}{l}\text { KMM437, } \\
\text { 428/ ACR82 }\end{array}$ & & 13 & & & & Ifs after birth \\
\hline Origanum majorana L. & $\begin{array}{l}\text { Mejorana/ } \\
\text { Tomillo } \\
\end{array}$ & ACR24 & & 13 & & & & Colic \\
\hline Origanum vulgare L. & Oregano & KMM509 & & 13 & 17 & & & Colic \\
\hline $\begin{array}{l}\text { Otholobium glandulosum (L.) } \\
\text { J.W. Grimes }\end{array}$ & Culen & $\begin{array}{l}\text { KMM419/ } \\
\text { AKT1134 } \\
\end{array}$ & & 10 & & & & $\mathrm{Dr}$ \\
\hline $\begin{array}{l}\text { Otholobium mexicanum (L.f.) } \\
\text { J.W. Grimes }\end{array}$ & Culen & ACR67 & & 14 & & & & $\mathrm{Dr}$ \\
\hline Rosmarinus officinalis L. & Romero & $\begin{array}{l}\text { ACR16/ } \\
\text { AKT1129 }\end{array}$ & & 17 & 11 & & & $\mathrm{Br}$ \\
\hline Salvia cuspidata Ruiz \& Pav. & Salvia Blanca & RBU/PL315 & & 18 & & & & $S$ \\
\hline Salvia discolor Kunth & Llatama & ISA151 & & 13 & & & & Cough \\
\hline Salvia sagittata Ruiz \& Pav. & Salvia Negra & RBU/PL318 & & 12 & & & & Cough \\
\hline Salvia sp. & Alamo Silvestre & ACR184 & & 14 & & & & Cough \\
\hline Salvia sp. & Hierba del Aire & AKT1160 & & & & & & $S$ \\
\hline Salvia sp. & $\begin{array}{l}\text { Hierba de los } \\
\text { sieta vientos }\end{array}$ & KMM572 & & & & & & $S$ \\
\hline Salvia sp. & Paja Amargoza & KMM567 & & & & & & $s$ \\
\hline Salvia sp. & Paja del Aire & ACR115 & & & & & & S \\
\hline
\end{tabular}




\begin{tabular}{|c|c|c|c|c|c|c|c|c|}
\hline \multirow[t]{2}{*}{$\begin{array}{l}\text { Plant Family } \\
\text { Species }\end{array}$} & \multirow[t]{2}{*}{ Common name } & \multirow[t]{2}{*}{$\begin{array}{l}\text { Collector } \\
\& \text { Col\# }\end{array}$} & \multicolumn{5}{|c|}{$\begin{array}{l}\text { Inhibition diameter } \\
(\mathrm{mm}) \text {. Blank cells } \\
\text { indicate lack of } \\
\text { antibacterial activity }\end{array}$} & \multirow[t]{2}{*}{$\begin{array}{l}\text { Traditional } \\
\text { application }\end{array}$} \\
\hline & & & $\begin{array}{l}\text { ఫे } \\
\text { ய่ }\end{array}$ & 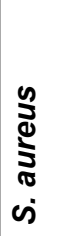 & 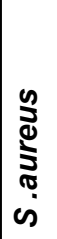 & 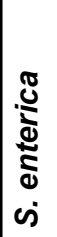 & 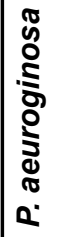 & \\
\hline Salvia sp. & Unquia Real & KMM550 & & & & & & $S$ \\
\hline Satureja pulchella (Kunth) Briq. & Panizara & KMM543 & & 11 & & & & $\mathrm{Br}$ \\
\hline $\begin{array}{l}\text { Satureja sericea (C. Presl \& } \\
\text { Benth.) Briq. }\end{array}$ & Romerio & $\begin{array}{l}\text { KMM397/ } \\
\text { ACR100 }\end{array}$ & & & & & & $\mathrm{S}$ \\
\hline $\begin{array}{l}\text { Scutellaria cf. scutellarioides } \\
\text { (Kunth) Harley }\end{array}$ & Poleo Gentil & ACR178 & & & & & & $S$ \\
\hline Stachys lanata Crantz & Veronica Macho & JULS13 & & 12 & & & & $\mathrm{Br}$ \\
\hline \multirow[t]{2}{*}{ Thymus vulgaris L. } & Tomillo & EHCHL169 & & 16 & & & & Cough \\
\hline & Salvia Real & ACR25 & & 18 & & & & $S$ \\
\hline \multicolumn{9}{|l|}{ Lauraceae } \\
\hline Cinnamomum verum J. Presl & Canela & KMM575 & & 14 & & & & $\mathrm{Br}$ \\
\hline Persea americana Mill. & Palta & $\begin{array}{l}\text { AKT1120/ } \\
\text { KMM444 }\end{array}$ & & 10 & & & & Cough \\
\hline \multicolumn{9}{|l|}{ Lichenes } \\
\hline Siphula sp. & Pelo de Pierda & ACR187 & & 10 & & & & Liver In \\
\hline \multicolumn{9}{|l|}{ Linaceae } \\
\hline Linum cf. usitatissimum L. & Linaza & KMM504 & & & & & & $\mathrm{K}$ \\
\hline \multicolumn{9}{|l|}{ Loganiaceae } \\
\hline Buddleja utilis Kraenzl. & Flora Blanca & AKT1131 & & & & & & Menstruation \\
\hline \multicolumn{9}{|l|}{ Lycopodiaceae } \\
\hline Huperzia sp. & Condor & AKT1170 & & & & & & S \\
\hline Huperzia sp. & Condor & KMM541 & & & & & & $S$ \\
\hline Huperzia sp. & Condor crespo & KMM477 & & & & & & $S$ \\
\hline Huperzia sp. & Condor Misha & KMM479 & & & & & & $S$ \\
\hline Huperzia sp. & Condor Purga & KMM482 & & & & & & $S$ \\
\hline Huperzia sp. & Condor Purga & AKT1212 & & & & & & $S$ \\
\hline Huperzia sp. & Corontilla & KMM391 & & & & & & $S$ \\
\hline Huperzia sp. & Enredadera & AKT1183 & & & & & & $\mathrm{S}$ \\
\hline Huperzia sp. & Trencilla blanca & KMM483 & & & & & & $S$ \\
\hline $\begin{array}{l}\text { Lycopodium thyoides Humb. } \\
\text { \& Bonpl. ex Willd. }\end{array}$ & Trencilla & $\begin{array}{l}\text { AKT1198, } \\
1191\end{array}$ & & & & & & $\mathrm{~S}$ \\
\hline Lycopodium sp. & Guamingo & AKT1206 & 10 & & & & & S \\
\hline Lycopodium sp. & Simba & ACR116 & & & & & & $S$ \\
\hline \multicolumn{9}{|l|}{ Lythraceae } \\
\hline Cuphea sp. & Hierba del Toro & KMM448 & & 13 & & & & $\mathrm{Bl}$ \\
\hline
\end{tabular}


Bussmann et al. - Proving that Traditional Knowledge Works: The antibacterial activity of Northern Peruvian medicinal plants

\begin{tabular}{|c|c|c|c|c|c|c|c|c|}
\hline \multirow[t]{2}{*}{$\begin{array}{l}\text { Plant Family } \\
\text { Species }\end{array}$} & \multirow[t]{2}{*}{ Common name } & \multirow[t]{2}{*}{$\begin{array}{l}\text { Collector } \\
\& \text { Col\# }\end{array}$} & \multicolumn{5}{|c|}{$\begin{array}{l}\text { Inhibition diameter } \\
(\mathrm{mm}) \text {. Blank cells } \\
\text { indicate lack of } \\
\text { antibacterial activity }\end{array}$} & \multirow[t]{2}{*}{$\begin{array}{l}\text { Traditional } \\
\text { application }\end{array}$} \\
\hline & & & نे & 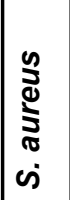 & 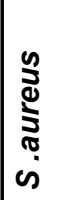 & 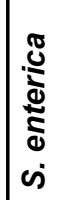 & 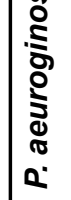 & \\
\hline Cuphea strigulosa Kunth & Sanguinaria & JULS33 & & 12 & & & & $\mathrm{BI}$ \\
\hline \multicolumn{9}{|l|}{ Malpighiaceae } \\
\hline $\begin{array}{l}\text { Banisteriopsis caapi (Spruce } \\
\text { ex Griseb.) C.V. Morton }\end{array}$ & Ayohuasca & ACR135 & & & & & & $S$ \\
\hline \multicolumn{9}{|l|}{ Malvaceae } \\
\hline Gossypium cf. barbadense L. & Algodon Pardo & AKT1227 & & & & & & W (dressing) \\
\hline Malva cf. parviflora L. & Malva rosa & AKT1200 & & 8 & & & & $\mathrm{Br}$ \\
\hline Malva cf. sylvestris L. & $\begin{array}{l}\text { Malva Blanca } \\
\text { Alta } \\
\end{array}$ & ACR8 & & & & & & W \\
\hline Malva sp. & Malva Real & AKT1201 & & & & & & $\mathrm{Br}$ \\
\hline $\begin{array}{l}\text { Ochroma cf. pyramidale } \\
\text { (Cav. ex Lam.) Urb. }\end{array}$ & Balsa & ACR206 & & & & & & Construction \\
\hline Urena cf. lobata L. & Buenas Horas & ACR185 & & & & & & Dementia \\
\hline \multicolumn{9}{|l|}{ Maranthaceae } \\
\hline $\begin{array}{l}\text { Monotagma plurispicatum } \\
\text { (Körn.) K. Schum. }\end{array}$ & Patiquina & ACR114 & 7 & & & & & $\mathrm{~S}$ \\
\hline \multicolumn{9}{|l|}{ Melastomataceae } \\
\hline Brachyotum naudinii Triana & Carcilleja & ACR140 & & $\sqrt{14}$ & & & & $\begin{array}{l}\text { Blood } \\
\text { circulation }\end{array}$ \\
\hline Brachyotum naudinii Triana & Zarcilleja & AKT1189 & & & & & & $\begin{array}{l}\text { Blood } \\
\text { circulation }\end{array}$ \\
\hline $\begin{array}{l}\text { Brachyotum tyrianthinum } \\
\text { J.F. Macbr. }\end{array}$ & $\overline{\text { Sarzilleja }}$ & EHCHL55 & & 10 & & & & $\begin{array}{l}\text { Blood } \\
\text { circulation }\end{array}$ \\
\hline $\begin{array}{l}\text { Miconia salicifolia ((Bonpl. } \\
\text { ex Naudin) Naudin }\end{array}$ & $\begin{array}{l}\text { Mocochol } \\
\text { Porotillo }\end{array}$ & $\begin{array}{l}\text { ACT204/ } \\
\text { KMM544 }\end{array}$ & & 11 & & & & Burns \\
\hline \multicolumn{9}{|l|}{ Menispermaceae } \\
\hline Abuta grandifolia (Mart.) Sandwith & Abuta & ACR136 & 10 & 12 & & 8 & & $\mathrm{C}$ \\
\hline \multicolumn{9}{|l|}{ Monimiaceae } \\
\hline Peumus boldus Molina & Boldo (Chilean) & AKT1132 & & 15 & & & & $\mathrm{~K}$ \\
\hline \multicolumn{9}{|l|}{ Moraceae } \\
\hline Brosimum rubescens Taub. & Palo Sangre & KMM570 & & & & & & $\mathrm{Ar}$ \\
\hline Ficus carica L. & Higo & ACR73 & & 8 & & & & $\overline{\mathrm{Db}}$ \\
\hline Ficus carica L. & Higo & AKT1128 & & & & & & $\mathrm{Db}$ \\
\hline \multicolumn{9}{|l|}{ Myrtaceae } \\
\hline Eucalyptus citriodora Hook. & citradora & $\begin{array}{l}\mathrm{KMM} \\
454\end{array}$ & & 20 & 10 & & & $\overline{\mathrm{Db}}$ \\
\hline
\end{tabular}




\begin{tabular}{|c|c|c|c|c|c|c|c|c|}
\hline \multirow[t]{2}{*}{$\begin{array}{l}\text { Plant Family } \\
\text { Species }\end{array}$} & \multirow[t]{2}{*}{ Common name } & \multirow[t]{2}{*}{$\begin{array}{l}\text { Collector } \\
\& \text { Col\# }\end{array}$} & \multicolumn{5}{|c|}{$\begin{array}{l}\text { Inhibition diameter } \\
(\mathrm{mm}) \text {. Blank cells } \\
\text { indicate lack of } \\
\text { antibacterial activity }\end{array}$} & \multirow[t]{2}{*}{$\begin{array}{l}\text { Traditional } \\
\text { application }\end{array}$} \\
\hline & & & نे & 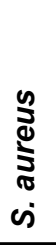 & 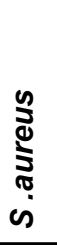 & 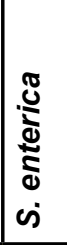 & 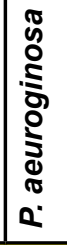 & \\
\hline Eucalyptus globulus Labill. & Eucalipto & $\begin{array}{l}\text { AKT1110/ } \\
\text { KMM408 }\end{array}$ & & 20 & 18 & & & $\mathrm{Br}$ \\
\hline Eugenia cf. obtusifolia Cambess. & Rumilanche & AKT1143 & & 14 & 18 & & & In \\
\hline Eugenia obtusifolia Cambess. & Limoncillo & ACR180, 76 & & 15 & & & & In \\
\hline Eugenia sp. & Arrayn & ACR19 & & 13 & & & & In \\
\hline $\begin{array}{l}\text { Myrcianthes discolor } \\
\text { (Kunth) McVaugh }\end{array}$ & Lanche & RBU/PL271 & & 16 & & & & In \\
\hline Psidium guajava L. & Guanabana & KMM339 & & 7 & & & & Cancer \\
\hline $\begin{array}{l}\text { Scutia spicata (Humb. \& } \\
\text { Bonpl. ex Willd.) Weberb. }\end{array}$ & Pial & ACR207 & & 12 & & & & S \\
\hline $\begin{array}{l}\text { Syzygium aromaticum (L.) } \\
\text { Merr. \& L.M. Perry }\end{array}$ & Clavo de olor & ACR188 & & & & & & Pain \\
\hline Syzygium jambos (L.) Alston & Poma Rosa & $\begin{array}{l}\text { GER173/ } \\
\text { ACR174 }\end{array}$ & & 10 & & & & $\mathrm{Dr}$ \\
\hline \multicolumn{9}{|l|}{ Olacaceae } \\
\hline $\begin{array}{l}\text { Heisteria acuminata } \\
\text { (Humb. \& Bonpl.) Engl. }\end{array}$ & Chuchu Wassi & KMM507 & 12 & 14 & & & & Cough \\
\hline Ximenia americana L. & Limoncillo & JULS184 & 12 & 10 & & & & $\begin{array}{l}\text { Menstrual } \\
\text { regulation }\end{array}$ \\
\hline \multicolumn{9}{|l|}{ Oleaceae } \\
\hline Jasminum sp. & Jasmin & AKT1211 & & 15 & & & & $\mathrm{~s}$ \\
\hline \multicolumn{9}{|l|}{ Onagraceae } \\
\hline Fuchsia sp. & Añasquero & AKT1187 & & & & & & $\mathrm{Ar}$ \\
\hline \multicolumn{9}{|l|}{ Orchidaceae } \\
\hline Aa paleacea (Kunth) Rchb.f. & Hierba Sola & $\begin{array}{l}\text { ACR144/ } \\
\text { AKT1158/ } \\
\text { KMM530 }\end{array}$ & & & & & & C \\
\hline Epidendrum sp. & Caballero & ACR168 & & & & & & $S$ \\
\hline Epidendrum sp. & Espadilla & ACR165 & & & & & & $\mathrm{s}$ \\
\hline Epidendrum sp. & $\begin{array}{l}\text { Hierba de la } \\
\text { Espada }\end{array}$ & AKT1177 & & 8 & & & & $S$ \\
\hline Epidendrum sp. & Hierba del Gallo & AKT1176 & & & & & & $S$ \\
\hline Epidendrum sp. & Lancilla & KMM484 & & & & & & $S$ \\
\hline Maxillaria sp. & Huome Huome & AKT1193 & & & & & & $S$ \\
\hline Stelis sp. & Hierba del Olor & KMM492 & & & & & & $S$ \\
\hline Stelis sp. & Oro & AKT1152 & & & & & & $\mathrm{s}$ \\
\hline
\end{tabular}


Bussmann et al. - Proving that Traditional Knowledge Works: The antibacterial activity of Northern Peruvian medicinal plants

\begin{tabular}{|c|c|c|c|c|c|c|c|c|}
\hline \multirow[t]{2}{*}{$\begin{array}{l}\text { Plant Family } \\
\text { Species }\end{array}$} & \multirow[t]{2}{*}{ Common name } & \multirow[t]{2}{*}{$\begin{array}{l}\text { Collector } \\
\& \text { Col\# }\end{array}$} & \multicolumn{5}{|c|}{$\begin{array}{l}\text { Inhibition diameter } \\
(\mathrm{mm}) \text {. Blank cells } \\
\text { indicate lack of } \\
\text { antibacterial activity }\end{array}$} & \multirow[t]{2}{*}{$\begin{array}{l}\text { Traditional } \\
\text { application }\end{array}$} \\
\hline & & & 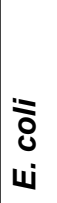 & 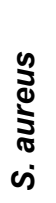 & 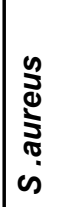 & 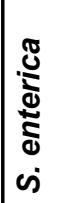 & 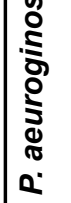 & \\
\hline \multicolumn{9}{|l|}{ Orobanchaceae } \\
\hline Escobedia grandiflora (L.f.) Kuntze & Azafran & JULS110 & & 22 & & & & $\mathrm{Br}$, Pneumonia \\
\hline \multicolumn{9}{|l|}{ Papaveraceae } \\
\hline Argemone mexicana L. & Cardo Santo & KMM433 & & & & & & $S$ \\
\hline Argemone mexicana L. & Cardo Santo & $\begin{array}{l}\text { ACR61/ } \\
\text { AKT1135 }\end{array}$ & & & 16 & & & $\mathrm{~S}$ \\
\hline \multicolumn{9}{|l|}{ Passifloraceae } \\
\hline Malesherbia ardens J.F. Macbr. & Veronica & AKT1232 & & 9 & & & & $\mathrm{Br}$ \\
\hline Passiflora ligularis A. Juss. & Hoja de granada & KMM420 & & 8 & & & & In \\
\hline Passiflora ligularis A. Juss. & $\begin{array}{l}\text { Hoja de } \\
\text { granadilla }\end{array}$ & $\begin{array}{l}\text { AKT1097/ } \\
\text { AKT1105/ } \\
\text { KMM420 }\end{array}$ & & & & & & $\ln$ \\
\hline Passiflora punctata L. & Norgo & KMM510 & & & & & & Menstrual pain \\
\hline Passiflora quadrangularis $\mathrm{L}$. & Ajo Sacha & ACR121 & & & & & & Menstrual pain \\
\hline Passiflora sp. & $\begin{array}{l}\text { Hierba del } \\
\text { Partero }\end{array}$ & AKT1122 & & & & & & Menstrual pain \\
\hline \multicolumn{9}{|l|}{ Phyllanthaceae } \\
\hline Phyllanthus niruri L. & Chanca Piedra & $\begin{array}{l}\text { KMM517/ } \\
\text { AKT1151 }\end{array}$ & & 18 & & & & In \\
\hline Phyllanthus urinaria L. & Chanca Piedra & JULS133 & & 14 & & & & In \\
\hline \multicolumn{9}{|l|}{ Phytolaccaceae } \\
\hline Petiveria alliacea $\mathrm{L}$. & Mocura & $\begin{array}{l}\text { ACR52/ } \\
\text { KMM447 } \\
\end{array}$ & & & & & & $S$ \\
\hline Phytolacca bogotensis Kunth & Ailambo & KMM457 & & 7 & & & & $\begin{array}{l}\text { Malaria, } \\
\text { Dengue, } \\
\text { Yellow Fever }\end{array}$ \\
\hline $\begin{array}{l}\text { Gallesia integrifolia (Spreng.) } \\
\text { Harms }\end{array}$ & Palo de Ajo & ACT116 & & 19 & & & & $\mathrm{Br}$ \\
\hline \multicolumn{9}{|l|}{ Piperaceae } \\
\hline Peperomia fraseri C.DC. & Hierba de Dolor & AKT1133 & & & & & & $S$ \\
\hline $\begin{array}{l}\text { Peperomia inaequalifolia } \\
\text { Ruiz. \& Pav. }\end{array}$ & Congona & $\begin{array}{l}\text { KMM534/ } \\
\text { AKT1148 }\end{array}$ & & & & & & $S$ \\
\hline Peperomia quadrifolia (L.) Kunth & Piri Piri & KMM532 & & & & & & $S$ \\
\hline Peperomia sp. & Congonilla & AKT1190 & & & & & & $S$ \\
\hline Peperomia sp. & Lancetillo & ACR21 & & & & & & $\mathrm{S}$ \\
\hline Piper acutifolium Ruiz.\& Pav. & Matico (sierra) & ACR15 & & & & & & Liver In \\
\hline
\end{tabular}




\begin{tabular}{|c|c|c|c|c|c|c|c|c|}
\hline \multirow[t]{2}{*}{$\begin{array}{l}\text { Plant Family } \\
\text { Species }\end{array}$} & \multirow[t]{2}{*}{ Common name } & \multirow[t]{2}{*}{$\begin{array}{l}\text { Collector } \\
\& \text { Col\# }\end{array}$} & \multicolumn{5}{|c|}{$\begin{array}{l}\text { Inhibition diameter } \\
(\mathrm{mm}) \text {. Blank cells } \\
\text { indicate lack of } \\
\text { antibacterial activity }\end{array}$} & \multirow[t]{2}{*}{$\begin{array}{l}\text { Traditional } \\
\text { application }\end{array}$} \\
\hline & & & $\begin{array}{l}\text { ¿े } \\
\text { uं }\end{array}$ & 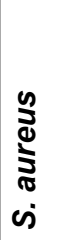 & 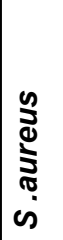 & 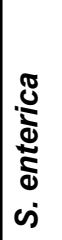 & 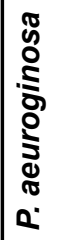 & \\
\hline Piper aduncum L. & Matico & $\begin{array}{l}\text { ACR12/ } \\
\text { AKT1150 }\end{array}$ & 12 & & & & & $\mathrm{~W}, \mathrm{Br}$ \\
\hline \multicolumn{9}{|l|}{ Plantaginaceae } \\
\hline Galvezia fruticosa J.F. Gmel. & Macacha & ACR64 & & & & & & $\mathrm{Ar}$ \\
\hline Plantago linearis Kunth & Llanten Serrano & JULS35 & & 10 & & & & W \\
\hline Plantago major L. & Ilanten & KMM411 & & 11 & & & & $\mathrm{Br}$ \\
\hline Plantago sericea Ruiz. \& Pav. & Pajilla blanca & ACR186 & & & & & & $S$ \\
\hline $\begin{array}{l}\text { Plantago sericea Ruiz. \& Pav. } \\
\text { var. lanuginosa Griseb. }\end{array}$ & Paja Blanca & $\begin{array}{l}\text { KMM499/ } \\
\text { AKT1182/ } \\
\text { ACR186 }\end{array}$ & & 13 & 15 & & & $\begin{array}{l}\text { Vaginal } \\
\text { discharge }\end{array}$ \\
\hline \multicolumn{9}{|l|}{ Poaceae } \\
\hline Arundo donax L. & Carrizo & KMM389 & & 12 & & & & Haemorrhoids \\
\hline Cymbopogon citratus (DC.) Stapf & Hierba Luisa & ACR5 & & & & & & Panacea \\
\hline Cynodon dactylon (L.) Pers. & Gramadulce & $\begin{array}{l}\text { KMM450/ } \\
\text { ACR64 }\end{array}$ & & & & & & Ovarian cysts \\
\hline Digitaria ciliaris (Retz.) Koeler & Pata de Gallina & JULS220 & & 8 & & & & S \\
\hline Distichlis spicata (L.) Greene & Gramadulce & AKT1096 & & & & & & $S$ \\
\hline $\begin{array}{l}\text { Gynerium sagittatum (Aubl.) } \\
\text { P. Beauv. }\end{array}$ & Carrizo & ACR47 & & & & & & $S$ \\
\hline Saccharum officinarum L. & Cana cana & $\begin{array}{l}\text { AKT121/ } \\
\text { KMM502 }\end{array}$ & & & & & & $\mathrm{K}$ \\
\hline & Barra de oro & KMM415 & & & & & & $S$ \\
\hline \multicolumn{9}{|l|}{ Polemoniaceae } \\
\hline Cantua buxifolia Juss. ex Lam. & $\begin{array}{l}\text { Cantuta o } \\
\text { Cando }\end{array}$ & ACR86 & & & & & & $\mathrm{S}$ \\
\hline Cantua quercifolia Juss. & Adormidora & AKT1161 & & & & & & $\mathrm{S}$ \\
\hline \multicolumn{9}{|l|}{ Polygonaceae } \\
\hline Polygonum hydropiperoides Michx. & Pica Pica & $\begin{array}{l}\text { ACR80/ } \\
\text { JULS223 }\end{array}$ & & 9 & & & & W \\
\hline Rumex crispus L. & Mala Hierba & KMM496 & & & & & & K \\
\hline \multicolumn{9}{|l|}{ Polypodiaceae } \\
\hline \multirow[t]{2}{*}{ Polypodium cf. crassifolium L. } & Calaguala & AKT1137 & & & & & & $\mathrm{K}$ \\
\hline & Contra Hierba & KMM464 & & & 9 & & & $\mathrm{~S}$ \\
\hline \multicolumn{9}{|l|}{ Proteaceae } \\
\hline Oreocallis grandiflora (Lam.) R. Br. & Proteaceae & $\begin{array}{l}\text { ACR176/ } \\
\text { KMM514/ } \\
\text { AKT1173 }\end{array}$ & & 10 & & & & $\mathrm{~K}$ \\
\hline
\end{tabular}


Bussmann et al. - Proving that Traditional Knowledge Works: The antibacterial activity of Northern Peruvian medicinal plants

\begin{tabular}{|c|c|c|c|c|c|c|c|c|}
\hline \multirow[t]{2}{*}{$\begin{array}{l}\text { Plant Family } \\
\text { Species }\end{array}$} & \multirow[t]{2}{*}{ Common name } & \multirow[t]{2}{*}{$\begin{array}{l}\text { Collector } \\
\text { \& Col\# }\end{array}$} & \multicolumn{5}{|c|}{$\begin{array}{l}\text { Inhibition diameter } \\
(\mathrm{mm}) \text {. Blank cells } \\
\text { indicate lack of } \\
\text { antibacterial activity }\end{array}$} & \multirow[t]{2}{*}{$\begin{array}{l}\text { Traditional } \\
\text { application }\end{array}$} \\
\hline & & & $\begin{array}{l}\bar{\delta} \\
\text { แं }\end{array}$ & 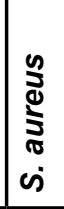 & 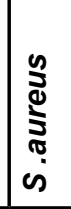 & 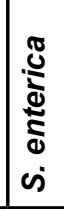 & 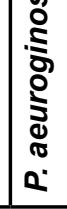 & \\
\hline \multicolumn{9}{|l|}{ Pteridaceae } \\
\hline $\begin{array}{l}\text { Argyrochosma nivea } \\
\text { (Poir.) Windham }\end{array}$ & Doradillo & KMM460 & & & & & & $S$ \\
\hline Cheilanthes pruinata Kaulf. & Cuty Cuty & KMM461 & & 13 & & & & $S$ \\
\hline Cheilanthes sp. & Cuti Cuti & AKT1108 & & 14 & & & & $\mathrm{~S}$ \\
\hline Jamesonia alstonii A.F. Tryon & Baston del Inca & ACR112 & & & & & & $S$ \\
\hline $\begin{array}{l}\text { Notholaena sulphurea } \\
\text { (Cav.) L. Sm. }\end{array}$ & Doradilla & KMM458 & & & & & & $S$ \\
\hline \multicolumn{9}{|l|}{ Ranunculaceae } \\
\hline $\begin{array}{l}\text { Laccopetalum giganteum } \\
\text { (Wedd.) Ulbr. }\end{array}$ & Pacra & AKT1119 & & 9 & & & & $\mathrm{Br}$ \\
\hline Ranunculus krapfia DC. ex Deless. & Marrajudio & ACR179 & & & & & & $S$ \\
\hline Thalictrum decipiens B. Bovin & Chontilla & ISA15 & 12 & 14 & & & & Mumps \\
\hline \multicolumn{9}{|l|}{ Rosaceae } \\
\hline Cydonia oblonga Mill. & Membrillo & JULS194 & & 11 & & & & Depression \\
\hline Cydonia oblonga Mill. & Membrillo & ACR56 & & & & & & Depression \\
\hline $\begin{array}{l}\text { Margyricarpus pinnatus (Lam.) } \\
\text { Kuntze }\end{array}$ & $\begin{array}{l}\text { China Lincla } \\
\text { Verde }\end{array}$ & ACR146 & & 8 & & & & 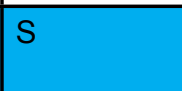 \\
\hline Polylepis racemosa Ruiz. \& Pav. & Quinal & ACR3 & & 14 & & & & If after birth \\
\hline Prunus serotina Ehrh. & Capuli & ACR172 & & & & & & $\mathrm{Ar}$ \\
\hline $\begin{array}{l}\text { Prunus serotina Ehrh. ssp. } \\
\text { capuli (Cav.) McVaugh }\end{array}$ & Helialiso & EHCHL94 & & 12 & & & & $W$ \\
\hline Rubus robustus C. Presl. & Sarsa mora & ACR70 & & & 16 & & & $\mathrm{Br}$ \\
\hline Sanguisorba minor Scop. & Pinpinela & ACR23 & & 13 & 13 & & & $\begin{array}{l}\text { Menstrual } \\
\text { regulation } \\
\end{array}$ \\
\hline & Ornamo Leon & AKT1214 & & & & & & $S$ \\
\hline \multicolumn{9}{|l|}{ Rubiaceae } \\
\hline Cinchona officinalis L. & Cascarilla & $\begin{array}{l}\text { ACR123/ } \\
\text { KMM525 }\end{array}$ & & 8 & & & & Cough \\
\hline Morinda citrifolia L. & Noni & ACR160 & & & & & & Panacea \\
\hline $\begin{array}{l}\text { Uncaria tomentosa (Willd. } \\
\text { ex Roem \& Schult.) DC. }\end{array}$ & Uña de Gato & ACR198 & 8 & 10 & & & & $\mathrm{Br}$ \\
\hline \multicolumn{9}{|l|}{ Rutaceae } \\
\hline Citrus limetta Risso & Lima & KMM425 & & 10 & & & & $\mathrm{~N}$ \\
\hline Citrus limon (L.) Osbeck & Limon & KMM424 & & & & & & $\mathrm{K}$ \\
\hline Citrus sinensis (L.) Osbeck & Naranja & JULS202 & & 16 & & & & $\mathrm{~N}$ \\
\hline
\end{tabular}




\begin{tabular}{|c|c|c|c|c|c|c|c|c|}
\hline \multirow[t]{2}{*}{$\begin{array}{l}\text { Plant Family } \\
\text { Species }\end{array}$} & \multirow[t]{2}{*}{ Common name } & \multirow[t]{2}{*}{$\begin{array}{l}\text { Collector } \\
\& \text { Col\# }\end{array}$} & \multicolumn{5}{|c|}{$\begin{array}{l}\text { Inhibition diameter } \\
(\mathrm{mm}) \text {. Blank cells } \\
\text { indicate lack of } \\
\text { antibacterial activity }\end{array}$} & \multirow[t]{2}{*}{$\begin{array}{l}\text { Traditional } \\
\text { application }\end{array}$} \\
\hline & & & $\begin{array}{l}\grave{8} \\
\text { u் }\end{array}$ & ڤ⿱丶万⿰亻 & 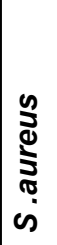 & 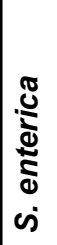 & 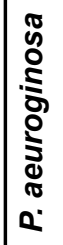 & \\
\hline Ruta graveolens L. & Ruda Seca & $\begin{array}{l}\text { AKT1105/ } \\
\text { KMM430 }\end{array}$ & & 14 & & & & $\mathrm{Ab}$ \\
\hline \multicolumn{9}{|l|}{ Salicaceae } \\
\hline Salix chilensis Molina & Sause & $\begin{array}{l}\text { ACR42/ } \\
\text { AKT1006 }\end{array}$ & & 12 & & & & Malaria, Fever \\
\hline \multicolumn{9}{|l|}{ Santalaceae } \\
\hline Phoradendron sp. & $\begin{array}{l}\text { Suelda con } \\
\text { suelda }\end{array}$ & ACR189 & 7 & & 10 & & & S \\
\hline \multicolumn{9}{|l|}{ Scrophulariaceae } \\
\hline Capraria peruviana Benth. & Flor Arenilla & RBU/PL374 & & 11 & & & & $\mathrm{~K}$ \\
\hline \multirow[t]{2}{*}{ Capraria peruviana Benth. } & Te de Judio & KMM574 & & & 12 & & & $\mathrm{~K}$ \\
\hline & Chiciricoma & KMM440 & & & 17 & & & W \\
\hline \multicolumn{9}{|l|}{ Smilacaceae } \\
\hline Smilax kunthii Killip \& C.V. Morton & Palo de la China & KMM20 & 16 & 18 & & & & Cancer \\
\hline Smilax sp. & Palo China & KMM516 & & 10 & & & & Cancer \\
\hline \multicolumn{9}{|l|}{ Solanaceae } \\
\hline Brugmansia candida Pers. & Misha Blanca & KMM564 & & & & 8 & & S \\
\hline $\begin{array}{l}\text { Brugmansia sanguinea (Ruiz \& } \\
\text { Pav.) D. Don }\end{array}$ & Misha & KMM528 & & & & & & $S$ \\
\hline Brugmansia sp & Misha & ACR90 & & & & & & $\mathrm{S}$ \\
\hline Brugmansia sp & Misha & AKT1149 & & & & & & S \\
\hline $\begin{array}{l}\text { Brugmansia suaveolens (Humb. \& } \\
\text { Bonpl. ex Willd.) Bercht. \& C. Presl }\end{array}$ & Floripondio & AKT1116 & & & & & & $S$ \\
\hline Capsicum chinense Jacq. & Aji Panca & GER203 & 9 & 15 & & & & $\mathrm{~S}$ \\
\hline Cestrum auriculatum L'Hér. & $\begin{array}{l}\text { Hierba Santa } \\
\text { (Sierra) }\end{array}$ & ACR36 & & 10 & & & & W \\
\hline Cestrum humboldtii Francey & Hierba Santa & ACR83 & & 9 & & & & W \\
\hline Cestrum sp. & Agrasejo & AKT1121 & & & & & & W \\
\hline Cestrum sp. & Hierba Santa & KMM426 & & & & & & W \\
\hline Cestrum strigilatum Ruiz \& Pav. & Santa Maria & JULS245 & 13 & 19 & & & & $\begin{array}{l}\text { Menstrual } \\
\text { regulation }\end{array}$ \\
\hline Datura ferox L. & Floripondio & KMM441, 582 & & & & & & $\mathrm{~S}$ \\
\hline Lycopersicon hirsutum Dunal & $\begin{array}{l}\text { Ambulluco } \\
\text { de Muerto }\end{array}$ & ISA31 & & 26 & & & & S \\
\hline Nicotiana tabacum L. & Tabaco & KMM388, 557 & & 8 & & & & S \\
\hline $\begin{array}{l}\text { Nolana cf. humifusa } \\
\text { (Gouan) I.M. Johnst. }\end{array}$ & $\begin{array}{l}\text { Hierba de } \\
\text { Señorita }\end{array}$ & AKT1124 & & & & & & $S$ \\
\hline
\end{tabular}


Bussmann et al. - Proving that Traditional Knowledge Works: The antibacterial activity of Northern Peruvian medicinal plants

\begin{tabular}{|c|c|c|c|c|c|c|c|c|}
\hline \multirow[t]{2}{*}{$\begin{array}{l}\text { Plant Family } \\
\text { Species }\end{array}$} & \multirow[t]{2}{*}{ Common name } & \multirow[t]{2}{*}{$\begin{array}{l}\text { Collector } \\
\& \text { Col\# }\end{array}$} & \multicolumn{5}{|c|}{$\begin{array}{l}\text { Inhibition diameter } \\
(\mathrm{mm}) \text {. Blank cells } \\
\text { indicate lack of } \\
\text { antibacterial activity }\end{array}$} & \multirow[t]{2}{*}{$\begin{array}{l}\text { Traditional } \\
\text { application }\end{array}$} \\
\hline & & & $\begin{array}{l}\bar{\delta} \\
\text { 山ं }\end{array}$ & 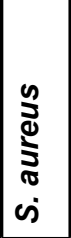 & 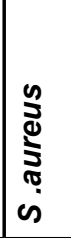 & 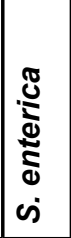 & 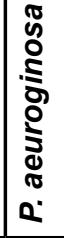 & \\
\hline Solanum americanum Mill. & $\begin{array}{l}\text { Hierba Moral } \\
\text { Cushay }\end{array}$ & ACR37, 99 & & 16 & & & & Sinusitis \\
\hline Solanum mammosum L. & Torito & AKT1138 & & & & & & $S$ \\
\hline \multicolumn{9}{|l|}{ Tropaeolaceae } \\
\hline Tropaeolum minus $\mathrm{L}$. & Mastuerzo & JULS81 & & 17 & & & & $\begin{array}{l}\text { In of the } \\
\text { stomach }\end{array}$ \\
\hline \multicolumn{9}{|l|}{ Ulmaceae } \\
\hline Celtis loxensis C.C. Berg & Palo Huaco & KMM561 & & 6 & & & & Fertility, $\mathrm{Br}$ \\
\hline \multicolumn{9}{|l|}{ Urticaceae } \\
\hline Pilea microphylla (L.) Liebm. & Contra Hierba & RBU/PL282 & & 8 & & & & $\mathrm{~K}$ \\
\hline Urtica magellanica Juss. ex Poir. & Ortiga Negra & ACR72 & & & & & & $\mathrm{BI}$ \\
\hline Urtica urens L. & Chin Chin & ACR199 & & & & & & $S$ \\
\hline \multicolumn{9}{|l|}{ Verbenaceae } \\
\hline $\begin{array}{l}\text { Aloysia scorodonioides } \\
\text { (Kunth) Cham. }\end{array}$ & Santa Maria & ACR43 & & 12 & & & & $\begin{array}{l}\text { Depression, } \\
\text { Pain }\end{array}$ \\
\hline Aloysia triphylla Royle & Cedron & KMM398 & & 13 & & & & $\begin{array}{l}\text { Depression, } \\
\text { Pain }\end{array}$ \\
\hline Aloysia triphylla Royle & Cedron & $\begin{array}{l}\text { AKT1126/ } \\
\text { ACR159 }\end{array}$ & & & & & & $\begin{array}{l}\text { Depression, } \\
\text { Pain }\end{array}$ \\
\hline Lantana scabiosiflora Kunth & Pacha Rosa & $\begin{array}{l}\text { AKT1123/ } \\
\text { ACR50 }\end{array}$ & & & & & & Cold \\
\hline Lantana sp. & $\begin{array}{l}\text { Hierba del } \\
\text { Hombre }\end{array}$ & AKT1202 & & & 9 & & & Cold \\
\hline \multirow[t]{2}{*}{ Verbena litoralis Kunth } & Verbena & JULS77 & & 12 & & & & W \\
\hline & Hierba de Susto & AKT1210 & & & & & & $\mathrm{S}$ \\
\hline \multicolumn{9}{|l|}{ Violaceae } \\
\hline Viola sp. & Pensamiento & ACR27 & & & & & & $S$ \\
\hline Viola sp. & Violeta & KMM426 & & & & & & $S$ \\
\hline Viola tricolor L. & Cinta de Novia & ACR195 & & & & & & $S$ \\
\hline \multicolumn{9}{|l|}{ Zingiberaceae } \\
\hline \multirow[t]{2}{*}{ Zingiber officinale Roscoe } & Gengibre & ACR196 & & & & & & $\mathrm{Br}$ \\
\hline & $\begin{array}{l}\text { Chimipampana } \\
\text { Blanca }\end{array}$ & KMM485 & & 12 & & & & $w$ \\
\hline \multicolumn{9}{|l|}{ Unknown } \\
\hline & Ajo Caspi & KMM518 & & 9 & & & & $\mathrm{~S}$ \\
\hline & Ajo Caspi & ACR133 & & & & & & $S$ \\
\hline
\end{tabular}




\begin{tabular}{|c|c|c|c|c|c|c|c|c|}
\hline \multirow[t]{2}{*}{$\begin{array}{l}\text { Plant Family } \\
\text { Species }\end{array}$} & \multirow[t]{2}{*}{ Common name } & \multirow[t]{2}{*}{$\begin{array}{l}\text { Collector } \\
\& \text { Col\# }\end{array}$} & \multicolumn{5}{|c|}{$\begin{array}{l}\text { Inhibition diameter } \\
(\mathrm{mm}) \text {. Blank cells } \\
\text { indicate lack of } \\
\text { antibacterial activity }\end{array}$} & \multirow[t]{2}{*}{$\begin{array}{l}\text { Traditional } \\
\text { application }\end{array}$} \\
\hline & & & $\begin{array}{l}\bar{\delta} \\
\text { ù } \\
\text { uं }\end{array}$ & 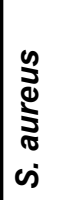 & 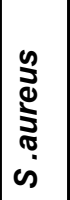 & 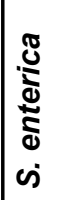 & 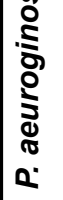 & \\
\hline & Anti ajo & AKT1219 & & & & & & $S$ \\
\hline & Arnica & ACR193 & & 11 & & & 2 & $W$ \\
\hline & $\begin{array}{l}\text { Bejuco de } \\
\text { montaña }\end{array}$ & ACR173 & & & & & & $S$ \\
\hline & Bledaco & KMM501 & & 13 & & & & \\
\hline & $\begin{array}{l}\text { Canchalagua } \\
\text { Morada }\end{array}$ & ACR143 & & & & & & $S$ \\
\hline & Cardo Bendito & KMM508 & & & & & & $S$ \\
\hline & Chimipanpana & AKT1139 & & & & & & $S$ \\
\hline & Chivato & KMM569 & & & & & & $S$ \\
\hline & Choloque & ACR84 & & & & & & $S$ \\
\hline & Cina Cina & ACR164 & & & & & & $S$ \\
\hline & Contra Hechizo & ACR106 & & & & & & $S$ \\
\hline & Cucho & ACR161 & & & & & & $S$ \\
\hline & Flor Dracaena & KMM559 & & & & & & $S$ \\
\hline & Hercampuri & ACR200 & & & & & & $S$ \\
\hline & Huarate & AKT1209 & & 11 & & & & $\mathrm{Db}$ \\
\hline & Lengua perro & ACR117 & & & & & & $S$ \\
\hline & Llanten Blanco & AKT1231 & & & 14 & & & $S$ \\
\hline & Llanten Blanco & AKT1123 & & & & & & $S$ \\
\hline & Milagroso & AKT1130 & & & & & & $S$ \\
\hline & Misqui Chilca & ACR137 & & & & & & $S$ \\
\hline & Motelilla & KMM488 & & & & & & $S$ \\
\hline & Paja del Susto & ACR104 & & & & & & $S$ \\
\hline & Pegajosa & ACR60 & & & & & & $S$ \\
\hline & Polen de Zapote & AKT1230 & & & & & & Tuberculosis \\
\hline & Poma Rosa & ACR174 & & & 8 & & & Nutrition \\
\hline & Violeta & KMM423 & & & & & & $\mathrm{S}$ \\
\hline & Yelama & ACR110 & & & & & & $S$ \\
\hline & Zarzaparrilla & AKT1136 & & & & & & $S$ \\
\hline
\end{tabular}



antibacterial activity of Northern Peruvian medicinal plants

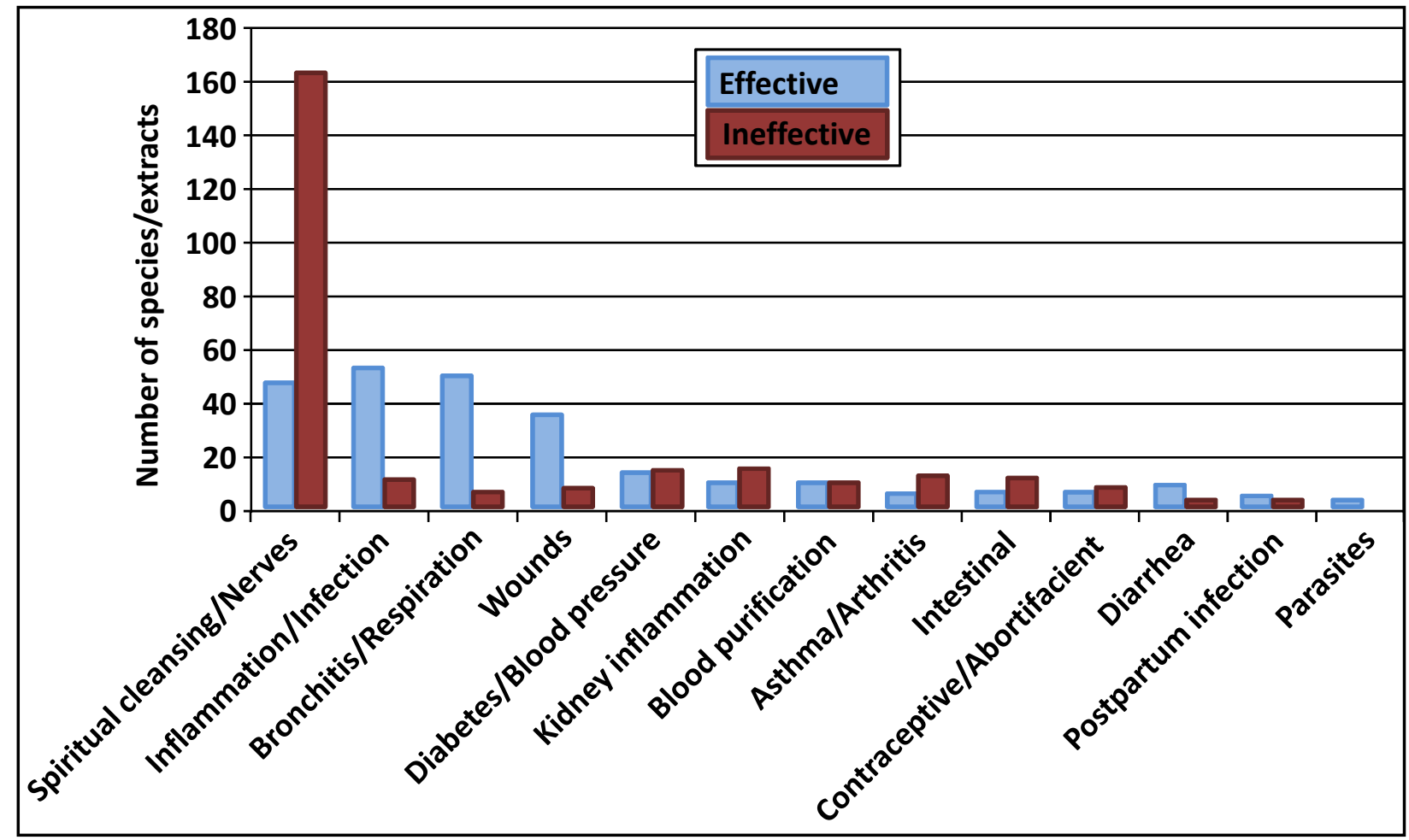

Figure 3. Antibacterial efficacy of plants traditionally used as anibacterials in the area of Trujillo and Chiclayo, northern Peru.

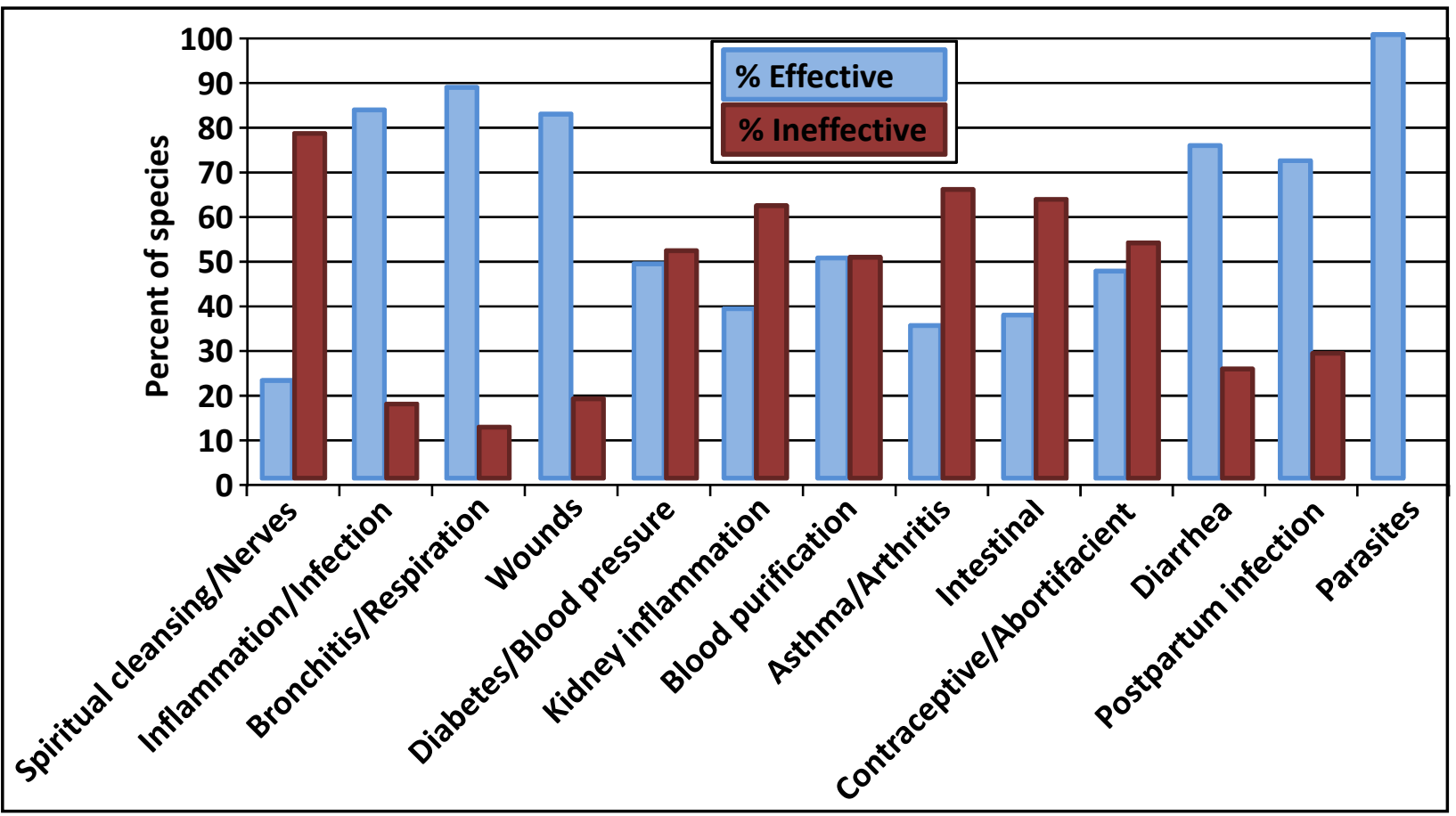

Figure 4. Efficacy percent per application category Trujillo and Chiclayo research area of northern Peru. 
Geranium sessiliflorum Cav., Hedyosmum racemosum (Ruiz. \& Pav.) G. Don., I. herbstii, Lycopersicon hirsutum Dunal, Mauria heterophylla Kunth, Phyllanthus niruri L., Porophyllum ruderale (Jacq.) Cass., Salvia cuspidata Ruiz \& Pav., Senecio chionogeton Wedd., Smilax kunthii Killip \& C.V. Morton, Tagetes erecta L. and Taraxacum officinale F.H. Wigg. showed high activity against S. aureus. The same holds true for Ephedra americana Humb. \& Bonpl. ex Willd., Gentianella bicolor (Wedd.) Fabris ex J.S. Pringle, Mandevilla trianae Woodson. However, extracts of these three species were highly inconsistent in their efficacy.

\section{Discussion}

The results of the presented study give potentially interesting leads for future antibiotic research. They do however also give close insight into traditional plant selection, and last, caution against the simple transfer of traditional applications into Western science. The comparison of closely related species traditionally employed for different purposes (e.g., different Alternanthera spp., Passiflora spp., Senecio spp. and Salvia spp. for spiritual purposes and against bacterial infections) showed that the "spiritual" species normally were not effective against bacteria, while the species used as antibacterials had increased effectiveness. The example of Plantago sericea Ruiz. \& Pav. var. sericea (used in seguros, no efficacy) and Plantago sericea Ruiz. \& Pav. var. lanuginosa Griseb. (used for vaginal infections, high efficacy against $S$. aureus) is a particularly compelling case that indicates the sophistication of traditional knowledge. However, we did find examples like Chuquiragua spp., where closely related species were used as antibacterials, but only one of them did in fact show efficacy, clearly indicating that in this case traditional knowledge did not produce reliable results.

On the other hand, extracts of the same species traditionally used to treat infections often produced vastly diverging results when collected from different localities. Good examples are Iresine herbstii Hook., Schinus molle L., Eustephia coccinea Cav., Oreopanax eriocephalus Harms, Myroxylon balsamum (L.) Harms, Spartium junceum L., or Gentianella dianthoides (Kunth) Fabris ex J.S. Pringle. These species did not produce particularly high inhibition rates in any case, and were not the first choice of healers when trying to find remedies for bacterial infections. Many traditional remedies for concepts like "kidney inflammation" did not produce any antibacterial results, which underlines that research into efficacy does need to closely take traditional disease concepts into account.

Many remedies used for spiritual healing and other noninfection purposes did show antibacterial efficacy in-vitro, but were not listed as such by the local healers. This might be explained by the fact that they either are very inconsistent in their activity (e.g., Brachyotum naudinii Triana, Cy- donia oblonga Mill., Hypericum laricifolium Juss., Hyptis sidifolia (L'Hér.) Briq., Lonicera japonica Thunb. ex Murray, Loricaria spp., Mentha X piperita L., M. trianae), or are so closely related that identification, especially when dried, can be a problem, e.g. in the case of Baccaris spp., Gentianella spp., and Valeriana spp., or are prone to toxic side effects like E. americana and Brugmansia spp.

Almost all remedies are traditionally prepared as water extracts, although ethanol (in the form of sugarcane spirit) is readily available. This might at a first glance seem astonishing, given the low efficacy of water extraction found in this study. However, initial results from Brine-Shrimp toxicity assays indicate that the ethanolic extracts are by far more toxic than water extracts of many species, and thus ethanolic extraction might in many cases not be suitable for application in patients. This again indicates the considerable sophistication and care with which traditional healers in northern Peru chose their remedies for a specific purpose.

\section{Conclusions}

Simple agar assays alone are not reliable for determining the efficacy of plants used in traditional medicine. The present study however confirms that simple laboratory methods are indeed well suited for the initial assessment of the efficacy of traditionally used medicinal plants in inhibiting bacterial growth. A comparison to the traditional uses also indicated that local knowledge can provide important leads for the development of new drugs: Our hypotheses that plants traditionally used as antibacterials do have a much higher incidence of efficacy than other medicinally used species, and that plants used for cleansing baths are more likely to have antibacterial properties than other species used for ritual purposes could be verified. However, if traditional knowledge is to serve as a lead, the results clearly indicate, that a very careful assessment of traditional disease concepts is needed in order to draw the right conclusions. It also needs to be taken into account that many plants are usually traditionally prepared in complex mixtures, and single species are rarely applied (Bussmann \& Sharon 2006, 2007). An efficacy analysis of these mixtures, as well as assays to evaluate the toxicity of single species as well as mixtures would be an interesting comparative study.

\section{Acknowledgments}

The presented study was financed through MIRT/MHIRT (Minority Health Disparity International Research and Training) a grant from the National Institutes of Health (Fund: 54112B MHIRT Program, Grant: G0000613). Fieldwork for this project was supported through the assistance of a large number of MIRT/MHIRT students and volunteers. Thanks to all of them. None of the work would have been possible without the invaluable collaboration 


\section{Bussmann et al. - Proving that Traditional Knowledge Works: The antibacterial activity of Northern Peruvian medicinal plants}

of our Peruvian colleagues, especially curanderas Julia Calderón, Isabel Chinguel, and Olinda Pintado, curanderos Germán Santisteban and Leoncio Carrión, and herbalists Manuel Bejarano, Elmer Cruz, and Iván Cruz. Thanks also go to Eric Rodriguez (Herbarium Truxillense, HUT) and Abundio Sagastegui, Segundo Leiva, and Mario Zapata (Herbario Antenor Orrego, HAO) for the use of their facilities and their assistance in plant identification.

\section{Literature Cited}

Baker, J., R. Borris, B. Carte, G. Cordell, D. Soejarto, G. Cragg, M. Gupta, M. Iwo, D. Madulid \& V. Tyler. 1995. Natural Product Discovery and Development: New Perspectives on International Collaboration. Journal of Natural Products 58(9):1325-1357.

Brako, L. \& J.L. Zarucchi. 1993. Editors of Catalogue of the Flowering Plants and Gymnosperms of Peru. Missouri Botanical Garden, Saint Louis, Missouri.

Breevort, P. 1998. The Booming U.S. Botanical Market: A New Overview. HerbalGram 44:33-46.

Bussmann, R.W. 2006. Manteniendo el balance de naturaleza y hombre. La diversidad florística andina y su importancia por la diversidad cultural - ejemplos del Norte de Perú y Sur de Ecuador. Arnaldoa 13(2):382-397.

Bussmann, R.W. \& D. Sharon. 2006. Traditional plant use in Northern Peru, Tracking two thousand years of health culture. Journal of Ethnobiology and Ethnomedicine 2:47.

Bussmann, R.W. \& D. Sharon. 2007. Plants of the Four Winds-Magic and Medicinal Flora of Peru. Graficart, Trujillo, Peru.

Bussmann, R.W., D. Sharon, F. Perez, D. Díaz, T. Ford, T. Rasheed, \& R. Silva. 2008. Antibacterial activity of Northern-Peruvian Medicinal Plants - A low cost laboratory approach to assess biological activity. Arnaldoa 15(1):127148.

Camino, L. 1992. Cerros, Plantas y Lagunas Poderosas: La Medicina al Norte del Perú. Lluvia Editores, Lima.

Camino, L. 1999. Cerros, Plantas y Lagunas Poderosas: La Medicina al Norte del Perú. 2nd edition. Lluvia Editores, Lima.

Cox, P. \& M. Balick. 1994. The ethnobotanical approach to drug discovery. Scientific American 270(6):82-87.

D’Agostino, M., F. De Simone, N. Tomais \& C. Pizza. 1995a. Constituents of Culcitium canescens. Fitoterapia $66: 550-551$.
D’Agostino, M., C. Pizza \& F. De Simona. 1995b. Flavone and flavonal glycosides from Desmodium molliculum. Fitoterapia 66:384-385.

De Feo, V. 1992. Medicinal and magical plants on northern Peruvian Andes. Fitoterapia 63:417-440.

Elisabetsky, E. \& C. Castilhos. 1990. Plants used as analgesics by Amazonian caboclos as a basis for selecting plants for investigation. International Journal of Crude Drug Research 28:309-320.

EsSalud/Organización Panamericana de Salud. 2000. Estudio Costo-Efectividad: Programa Nacional de Medicina Complementaria. Seguro Social de EsSalud (Study of Cost- Effectiveness: National Program in Complementary Medicine. Social Security of EsSalud). EsSalud/Organización Panamericana de Salud (Pan American Health Organization), Lima, Peru.

Farnsworth, N., O. Akerele, A. Bingel, D. Soejarto \& Z. Guo. 1985. Medicinal Plants in therapy. Bulletin of the World Health Organization 63(6):965-981.

Hammond, G.B., I.D. Fernandez, L. Villegas \& A.J. Vaisberg. 1998. A survey of traditional medicinal plants from the Callejon de Huaylas, Department of Ancash, Peru. Journal of Ethnopharmacology 61:17-30.

Joralemon, D. \& D. Sharon. 1993. Sorcery and Shamanism, Curanderos and Clients in Northern Peru. University of Utah Press, Salt Lake City.

Jørgensen, P.M. \& S. León-Yáñez. 1999. Editors of Catalogue of the Vascular Plants of Ecuador. Monographs in Systematic Botany from the Missouri Botanical Garden 75. Missouri Botanical Garden Press, St. Louis, Missouri.

Jørgensen, P.M. \& C. Ulloa Ulloa. 1994. Seed plants of the High Andes of Ecuador - a Checklist. Aarhus University (AAU) Reports 34:1-443.

Koneman, E.W., S.D. Allen, W.M. Janda, P.C. Schreckenber \& W.C. Wien. 1997. Color Atlas of Diagnostic Microbiology. Lippincott.

Lee, K.K., B.N. Zhou, D.G.I. Kingston, A.J. Vaisberg \& G.B. Hammond. 1999. Bioactiveindole alkaloids from the bark of Uncaria guianensis. Planta Medica 65:750-760.

McBride, J.F. 1936-1981. Editor of Flora of Peru. Fieldiana, Botany. Field Museum of Natural History, Chicago.

Muñoz, V. \& M. Sauvain. 2002. A search for natural bioactive compounds in Bolivia through a multidisciplinary approach: Part I. Evaluation of the antimalarial activity of plants usedby the Chacobo Indians. Journal of Ethnopharmacology 69:127-137. 
Neto, C., C. Owens, R. Langfield, A. Comeau, J. Onge, G. Hammond \& A. Vaisberg. 2002. Antibacterial activity of some Peruvian medicinal plants from Callejon de Huaylas. Journal of Ethnopharmacology 79:133-138.

Okuyama, E., K. Umeyama, S. Ohmori, M. Yamazaki, \& M. Satake. 1994. Pharmacologically active components from a Peruvian medicinal plant, Huira-Huira (Culcitium canescens H. \& B.) Chemical and Pharmaceutical Bulletin 42:2183-2186.

Perumal Samy, R. \& S. Ignacimuthu. 2000. Antibacterial activity in some medicinal plants used by tribes in Western Ghats, India. Journal of Ethnopharmacology 69:63-71.

Pestalozzi, H.U. 1998. Flora ilustrada altoandina. Herbario Nacional de Bolivia and Herbario Forestal Nacional Martín Cardenas, Cochabamba.

Polia, M. 1988. Las Lagunas de los Encantos - Medicina Tradicional Andina en el Peru septentrional. Central Peruana de Servicios, Lima.

Rodriguez, J., P. Pacheco, I. Razmilic, J.I. Loyola, G. Schmeda-Hirschmann \& C. Theoduloz. 1994. Hypotensive and diuretic effects of Equisetum bogotense and Fuchsia magellanica and micropropagation of E. bogotense. Phytotherapy Research 8:157-160.

Schultes, R.E. 1994. Amazonian ethnobotany and the search for new drugs. Pp. 106-115 in Ciba Foundation Symposium 185. Wiley, Chichester, U.K.

Sharon, D. 1978. Wizard of the Four Winds, A Shaman's Story. Free Press, New York.

Sharon, D. 1980. El Chamán de los Cuatro Vientos. Siglo veintiuno editores, México, District Federal.

Sharon, D. 1994. Tuno y sus colegas, notas comparativas. Pp. 128-147 in En el Nombre del Señor, Shamanes, demonios y curanderos del norte del Perú. Edited by L. Millones \& M. Lemlij. Australis S.A., Lima.

Sharon, D. 2000. Shamanismo y el Cacto Sagrado - Shamanism and the Sacred Cactus. San Diego Museum Papers 37. San Diego, California.

Sharon, D. \& R.W. Bussmann. 2006. Plantas Medicinales en la Obra del Obispo Don Baltasar Jaime Martínez Compañon (Siglo XVIII). Pp. 147-165 in Desde el exterior, El Perú y sus estudios. Edited by L. Millones \& T. Kato Tercer
Congreso Internacional de Peruanistas, Nagoya, Universidad Nacional Mayor de San Marcos, Departamento de Publicaciones, Lima.

Sparre, G. \& B. Harling. 1978-2009. Flora of Ecuador (various authors). Council for Nordic Publications in Botany. Botanical Museum, Copenhagen, Denmark.

Tropicos. 2010. Topicos.org, Missouri Botanical Garden. www.tropicos.org.

Ulloa Ulloa, C. \& P.M. Jørgensen. 1993. Arboles y arbustos de los Andes del Ecuador. Aarhus University (AAU) Reports 30:1-263.

Umana, E. \& O. Castro. 1990. Chemical constituents of Verbena littoralis. International Journal of Crude Drug Research 28:175-17.

United Nations Conference on Trade and Development. 2000. Systems and National Experiences for Protecting Traditional Knowledge, Innovations and Practices. Background Note by the UNCTAD Secretariat. Geneva, United Nations Conference on Trade and Development, (document reference TD/B/COM.1/EM.13/2).

Villegas, L., I. Fernandez, H. Maldonado, R. Torres, A. Zavaleta \& A. Vaisberg. 1997. Evaluation of the wound-healing activity of selected traditional medicinal plants. Journal of Ethnopharmacology 55:193-200.

World Health Organization. 1998. Report, Technical Briefing on Traditional Medicine. Forty-ninth Regional Committee Meeting, Manila, Philippines, 18 September 1998. Manila, WHO Regional Office for the Western Pacific.

World Health Organization. 1999a. Consultation Meeting on Traditional Medicine and Modern Medicine, Harmonizing the Two Approaches. Geneva, World Health Organization, (document reference (WP)TM/ICP/TM/001/ $\mathrm{RB} / 98-\mathrm{RS} / 99 / \mathrm{GE} / 32(\mathrm{CHN})$ ).

World Health Organization. 1999b. Traditional, Complementary and Alternative Medicines and Therapies. Washington DC, WHO Regional Office for the Americas/Pan American Health Organization (Working group OPS/ OMS).

World Health Organization. 2002. WHO Traditional Medicine Strategy 2002-2005. World Health Organization, Geneva. 